\title{
LOS TRIBUNALES AMBIENTALES EN CHILE. ¿UN AVANCE HACIA LA IMPLEMENTACIÓN DEL DERECHO DE ACCESO A LA JUSTICIA AMBIENTAL?
}

\author{
CAROLina RiQUELME SALAZAR \\ Becaria de investigación predoctoral del Departamento de Derecho Público \\ Universitat Rovira i Virgili \\ carolina.riquelme@urv.cat
}

Recibido: 16 de abril de 2013 / Aceptado: 31 de mayo de 2012

RESUMEN: El presente estudio pretende analizar el estado actual de la implementación del derecho de acceso a la justicia en materia ambiental en Chile. Con esta finalidad, se intentará, en primer lugar, esbozar un panorama general acerca del derecho de acceso a la justicia propiamente tal, para luego aplicar sus elementos a la realidad jurídica ambiental chilena. Se intentará verificar la situación de la implementación de este derecho de acceso existente antes de la entrada en vigor de la Ley $20.600 / 2012$, de 28 de junio, que crea los tribunales ambientales, y determinar si el nuevo panorama que ella supone significa un avance en dicho ámbito.

RESUM: El present estudi pretén analitzar l'estat actual de la implementació del dret d'accés a la justícia en matèria ambiental a Xile. Amb aquesta finalitat, s'intentarà, en primer lloc, esbossar un panorama general sobre el dret d'accés a la justícia pròpiament tal, per després aplicar els seus elements a la realitat jurídica ambiental xilena. S'intentarà verificar la situació de la implementació d'aquest dret d'accés existent abans de l'entrada en vigor de la Llei 20.600/2012 de 28 de juny, que crea els Tribunals Ambientals, i determinar si el nou panorama que ella suposa significa un avanç en aquest àmbit. 
ABSTRACT: This paper aims to analyze the current state of the implementation of the right of access to justice in environmental matters in Chile. To achieve this goal, we will try to sketch an overview about the right of access to justice, and then apply their elements to the Chilean environmental legal reality. We are going to attempt to verify the status of the implementation of this right of access before the entry into force of the Law of 28 June 20.600/2012, about Environmental Courts, and determine whether the new overview means it is an advance in this field.

PALABRAS CLAVE: Tribunal ambiental - Acceso a la justicia en materia ambiental - Chile.

PARAULES CLAU: Tribunal ambiental — Accés a la justícia en matèria ambiental — Xile.

KEYWORDS: Environmental Court — Access to Justice in Environmental Matters Chile.

SUMARIO: I. Breves antecedentes acerca del derecho de acceso a la justicia ambiental. 1. Conceptualización del derecho de acceso a la justicia en materia ambiental. 2. Elementos del derecho de acceso a la justicia ambiental. 2.1. Desarrollo de la normativa ambiental. 2.2. Cumplimiento de la normativa ambiental. 2.3. Autoridades idóneas para conocer los asuntos ambientales. 2.4. Mecanismos de resolución de conflictos ambientales que propendan a una resolución completa y expedita. 2.5. Legitimación activa. 2.6. Condiciones de igualdad en el acceso a la justicia ambiental. II. El derecho de acceso a la justicia ambiental en Chile. 1. La implementación del derecho de acceso a la justicia en materia ambiental en Chile antes de la instauración de los tribunales ambientales. 1.1. Desarrollo y aplicación de la normativa ambiental en Chile. 1.2. Autoridades idóneas para conocer los asuntos ambientales en Chile. 1.3. Mecanismos de resolución de conflictos ambientales en Chile. 1.4. Legitimación activa en los procesos sobre medio ambiente en Chile. 1.5. Condiciones de igualdad en el acceso a la justicia ambiental en Chile. 2. La creación de los tribunales ambientales: un nuevo panorama para la implementación del derecho de acceso a la justicia ambiental en Chile. 2.1. Desarrollo y aplicación de la normativa ambiental mediante la Ley 20.600/2012. 2.2. Autoridades idóneas para conocer los asuntos ambientales en la Ley 20.600/2012. 2.3. Mecanismos de resolución de conflictos ambientales establecidos en la Ley 20.600/2012. 2.4. Legitimación activa ante los tribunales ambientales chilenos. 2.5. Condiciones de igualdad en el acceso a la justicia ambiental en la Ley 20.600/2012. III. Reflexiones finales. IV. Referencias bibliográficas. V. Recursos en línea. VI. Normas y sentencias. 


\section{BREVES ANTECEDENTES ACERCA DEL DERECHO DE ACCESO A LA JUSTICIA AMBIENTAL}

\section{Conceptualización del derecho de acceso a la justicia en materia ambiental}

El reconocimiento del derecho de toda persona a vivir en un medio ambiente sano, libre de contaminación, determina que el Estado debe propender a su protección mediante la generación de normas específicas que reflejen el consenso social en relación con el modelo de desarrollo, la asunción de riesgos y el reparto de responsabilidades frente a este medio ambiente efectivamente protegido ${ }^{1}$. Asimismo, el Estado deberá prever los medios e instrumentos a través de los cuales se asegure el efectivo cumplimiento de dichas normas por parte de las administraciones y de los particulares.

El derecho de acceso a la justicia ambiental, como derecho procedimental ${ }^{2}$ que concretiza el derecho a vivir en un ambiente sano, constituye uno de los mecanismos a través del cual los ciudadanos participan en el control del cumplimiento de las normas ambientales, haciendo posible que una persona o grupo de personas puedan reclamar o demandar la protección efectiva de su derecho a vivir en un medio ambiente libre de contaminación mediante la vía jurisdiccional.

Es en tal sentido que seguimos la conceptualización del reputado jurista Raúl Brañes Ballesteros, por cuanto entiende el derecho de acceso a la justicia ambiental como "la posibilidad de obtener la solución expedita y completa por las autoridades judiciales de un conflicto jurídico de naturaleza ambiental, lo que supone que todas las personas están

\footnotetext{
${ }^{1}$ Cfr. JARIA I MANZANO, J., "El fundamento constitucional de los derechos de participación en materia de medio ambiente y su desarrollo en la Ley 27/2006", Pigrau Solé, A. (dir.), Acceso a la información, participación pública y acceso a la justicia en materia de medio ambiente: diez años del Convenio de Aarhus, Atelier, Barcelona, 2008, p. 122.

${ }^{2}$ Cierta doctrina ha considerado que la configuración del derecho a vivir en un medio ambiente sano como un derecho procedimental puede ser más eficaz para conseguir las finalidades pretendidas que su configuración como derecho sustantivo. En consecuencia, para obtener el objetivo perseguido por este derecho de índole colectivo, que resguarda intereses difusos, habrá de crearse un sistema de normas que apunten a desarrollar los aspectos más relevantes del contenido del derecho: el acceso a la información, a la participación ciudadana y a la justicia en materia ambiental. Cfr. JARIA I MANZANO, J., "El fundamento..." cit. pp. 133 y ss., y RAZQUIN LIZARRAGA, J. A. y RUIZ DE APODACA ESPINOSA, ÁNGEL, Información, participación y justicia en materia de medio ambiente. Comentario sistemático a la Ley 27/2006, de 18 de julio, Thomson Aranzadi, Navarra, 2007, pp. 105 y ss.
} 
en igualdad de condiciones para acceder a la justicia y para obtener resultados individual o socialmente justos"3.

\section{Elementos del derecho de acceso a la justicia ambiental}

Partiendo de la conceptualización del derecho de acceso a la justicia ambiental, resulta posible inferir los elementos que lo configuran como tal. Estos elementos constituyen en sí mismos una importante herramienta, toda vez que, confrontándolos con la práctica jurídica, permiten la verificación de los diversos obstáculos en la implementación de este derecho de acceso.

Una vez reconocida la existencia de tales obstáculos, las autoridades correspondientes podrán efectuar las modificaciones normativas pertinentes, cuyo objeto deberá propender al desarrollo y la evolución de este derecho procedimental.

Desde la óptica prevista se pueden distinguir los siguientes elementos a través de los cuales se manifiesta y concreta el derecho de acceso a la justicia en materia ambiental: el desarrollo y cumplimiento de la normativa ambiental, la existencia de autoridades idóneas para el conocimiento de asuntos de índole ambiental, la existencia de mecanismos de resolución de conflictos ambientales que propendan a una resolución completa y expedita, una amplia legitimación activa y el cumplimiento de ciertas condiciones que aseguren el principio de igualdad en el acceso al procedimiento que versa sobre materias ambientales.

\subsection{Desarrollo de la normativa ambiental}

En principio, se ha sostenido que el derecho de acceso a la justicia ambiental solamente podría tener lugar en un ordenamiento jurídico que reconozca el derecho a vivir en un ambiente adecuado ${ }^{4}$. Sin embargo, la mera declaración de este reconocimiento no es

\footnotetext{
${ }^{3}$ BRAÑES BALLESTEROS, R., "El acceso a la justicia ambiental en América Latina: Derecho Ambiental y Desarrollo Sostenible", Simposio Judicial Derecho Ambiental y Desarrollo Sostenible. El acceso a la justicia ambiental en América Latina, del 26 al 28 de enero de 2000, Ciudad de México, Programa de Naciones Unidas para el Medio Ambiente y Procuraduría Federal de Protección al Ambiente, Gobierno de México, p. 40.

${ }^{4}$ Cfr. RAZQUIN LIZARRAGA, J. A. y RUIZ DE APODACA ESPINOSA, Á., Información... cit. p. 376.
} 
suficiente para constituir el derecho de acceso a la justicia ambiental, sino que conforma la base para el desarrollo de un sistema normativo ambiental que tendrá por objeto implementar y proteger este derecho frente a posibles acciones u omisiones que, al sobrepasar los límites de los riesgos tecnológicos socialmente aceptados, causen daño al medio ambiente de tal forma que vulneren el derecho a vivir en un ambiente sano.

Al tratarse de una legislación en vías de formación, el derecho ambiental aún no ha uniformado los procedimientos para el conocimiento de conflictos de esta naturaleza tan singular. Ello puede significar que eventualmente, una vez planteado un problema de naturaleza jurídico-ambiental, la autoridad jurisdiccional competente tenga que resolver el conflicto sometido a su decisión en ausencia de normas ambientales específicas o bien mediante normas que no sean totalmente idóneas para el tratamiento del caso concreto.

En cualquiera de los casos mencionados, y conforme lo dispone el principio de inexcusabilidad, el tribunal llamado a conocer el asunto deberá de todos modos resolver el conflicto sometido a su decisión, aun cuando lo haga mediante la aplicación de mecanismos jurídicos que puedan resultar inadecuados para solucionar este tipo concreto de conflictos 5 .

\subsection{Cumplimiento de la normativa ambiental}

Para que se verifique en la práctica el acceso a la justicia ambiental, no basta que el ordenamiento jurídico reconozca el derecho a vivir en un ambiente sano y contemple normas que regulen este derecho y hagan posible su aplicación, es necesario además que efectivamente se cumpla ${ }^{6}$, en un primer estadio por parte de la ciudadanía y de la

\footnotetext{
${ }^{5}$ En muchas ocasiones la autoridad jurisdiccional, a falta de normas o procedimientos específicos, ha resuelto el conflicto ambiental conforme a las normas y los procedimientos civiles, que si bien pueden perseguir obtener una indemnización frente a la vulneración de un derecho subjetivo o interés individual, no son idóneos para perseguir la responsabilidad por intereses difusos que hayan sido vulnerados y la reparación del medio ambiente dañado. Cfr. BRAÑES BALLESTEROS, R., "El acceso..." cit., p. 53. Sobre la falta de idoneidad de las normas civiles para perseguir la reparación del medio ambiente dañado, véase también: JANA LINETZKY, A., SCHWENCKE SAINT-JEAN, J. P. y VARAS BRAUN, J. A., "La responsabilidad civil en el proyecto de la ley de bases del medio ambiente: una mirada crítica", Revista Derecho y Humanidades, núm. 2, 1992, p. 176, y VERGARA FISCHER, J., "La responsabilidad en la ley de bases del medio ambiente", Revista Derecho y Humanidades, núm. 2, 1992, p. 209.

${ }^{6}$ A este respecto, señala Ruiz de Apodaca que "la eficacia de las normas radica en su efectivo cumplimiento". Véase RUIZ DE APODACA ESPINOSA, A., "Nuevas perspectivas del acceso a la justicia en materia de medio ambiente", Pigrau Solé, A. y Casado Casado, L. (dirs.), Derecho ambiental y transformaciones de la actividad de las administraciones públicas, Barcelona, Atelier, 2010, p. 187.
} 
Administración general del Estado de forma voluntaria, y, en un segundo, por parte de las autoridades jurisdiccionales competentes cuando haya fallado la aplicación voluntaria por parte de la ciudadanía y del Estado ${ }^{7}$.

Se ha constatado que la legislación ambiental tiene un bajo nivel de aplicación en los diversos ámbitos de actuación, sea por parte de la ciudadanía en general, sea por parte de las autoridades administrativas y políticas, sea por parte de los órganos jurisdiccionales del Estado, "por razones que nunca se ponen en claro"8, lo que inevitablemente se verá reflejado como un obstáculo al ejercicio del derecho de acceso a la justicia ambiental ${ }^{9}$.

\section{3. $\quad$ Autoridades idóneas para conocer los asuntos ambientales}

Cada Estado es soberano para determinar los órganos competentes para conocer los asuntos de índole ambiental, siempre y cuando estos cumplan ciertos principios propios de un sistema democrático.

Stephen Stec, Susan Casey-Lefkowitz y Jerzy Jendroska, interpretando el Convenio de Aarhus sobre el acceso a la información, a la participación y a la justicia en materia de medio ambiente, señalan que el órgano encargado de conocer los conflictos que se susciten en la órbita jurídico-ambiental no necesariamente tienen que conformarse como

\footnotetext{
${ }^{7}$ Así lo ha entendido Baño León cuando señala que "la tutela judicial efectiva nunca puede constituir el remedio eficaz del derecho colectivo a la protección del medio ambiente ya que éste se sustancia en el plano normativo y en el adecuado desarrollo de los instrumentos de planificación y prevención que rendirán siempre mejores frutos que el recurso a tribunales. En realidad el recurso a los Tribunales supone el reconocimiento del fracaso de la normativa o de la escasa aceptación de las decisiones administrativas respecto de proyectos y actividades con incidencia sobre el medio ambiente". Frente a esta argumentación, Razquin Lizarraga y Ruiz de Apodaca Espinosa agregan: "Lamentablemente, la exigencia de la normativa ambiental se matiza en muchas ocasiones con su general incumplimiento por parte incluso de las propias Administraciones públicas y es necesario que se garantice el acceso a los medios de recurso administrativos y judiciales, con una legitimación amplia, a los ciudadanos". Véase RAZQUIN LIZARRAGA, J. A. y RUIZ DE APODACA ESPINOSA, Á., Información... cit., siguiendo a BAÑO LEÓN, J. M., "La tutela judicial del medio ambiente y la defensa de los intereses municipales", Esteve Pardo, J. (coord.), Derecho del medio ambiente y administración local, Fundación Democracia y Gobierno Local, 2. 'a ed., Barcelona, 2006, p. 384.

${ }^{8}$ BRAÑES BALLESTEROS, R., “El acceso...” cit., p. 51.

${ }^{9}$ La desidia en la aplicación voluntaria de la normativa ambiental, tanto por parte de la sociedad civil como por las autoridades administrativas con competencia ambiental, deriva básicamente de su estado de ignorancia y desaprensión ambiental, lo que solo será paliado una vez implementado el derecho de acceso a la información ambiental, que constituye una piedra fundamental en la construcción del Estado de derecho. En consecuencia, el acceso a la información ambiental constituye un requisito sine qua non para la implementación del derecho de acceso a la justicia ambiental. Cfr. BERMÚDEZ SOTO, J., "El acceso a la información pública y la justicia ambiental", Revista de Derecho de la Pontificia Universidad Católica de Valparaíso, núm. 34, $1^{\mathrm{er}}$ semestre de 2010, p. 595.
} 
un tribunal jurisdiccional, pudiendo también tratarse de un tribunal cuasijudicial que salvaguarde la garantía del debido proceso y el principio de independencia ${ }^{10}$.

Además, considerando la complejidad científico-técnica inherente a los conflictos relativos al medio ambiente, donde no basta el conocimiento de la disciplina jurídica, sino que abarca campos como la química, la biología, la economía o la sociología, entre otros, la autoridad encargada de su conocimiento debe estar adecuadamente preparada.

Si bien es cierto que el cumplimiento de los principios de imparcialidad e independencia, en general, no plantea ninguna novedad en los distintos ordenamientos jurídicos, la preparación de los órganos que deben conocer de esta clase de conflictos ha sido deficitaria en la mayoría de los casos, lo cual es consecuencia directa de la ineficiencia e ineficacia de la norma ambiental y su aplicación ${ }^{11} \mathrm{y}$, en menor medida, de la pasividad y resistencia de los órganos competentes para adaptarse a los cambios derivados de las nuevas necesidades sociales.

\subsection{Mecanismos de resolución de conflictos ambientales que propendan a una} resolución completa y expedita

La resolución de conflictos jurídicos de naturaleza ambiental se verifica a través de la aplicación de distintos mecanismos contemplados en cada ordenamiento jurídico.

Se ha observado que algunos países optan prioritariamente por un sistema de reclamo administrativo para el tratamiento del conflicto ambiental por considerarlo más expedito, con menores costos y más efectivo. Otros ordenamientos, en cambio, utilizan el sistema judicial ordinario ${ }^{12}$ para garantizar un estudio más detallado y acabado del

10 Cfr. STEC, S., CASEY-LEFKOWITZ, S. y JENDROSKA, J., The Aarhus Convention: An Implementation Guide, Naciones Unidas, Nueva York/Ginebra, 2000, p. 126.

${ }^{11}$ Recordemos que este obstáculo es propio de las nuevas disciplinas que aún se están desarrollando. Véanse los apartados I.2.1. y I.2.2. supra.

${ }^{12}$ El sistema judicial ambiental comprende, a su vez, la justicia constitucional (a través de la consagración de acciones constitucionales), la justicia civil (a través de la aplicación del sistema de responsabilidad por hecho ilícito o de las normas que regulan la propiedad), la justicia penal (directamente, a través de la tipificación de delitos contra el medio ambiente o indirectamente mediante la tipificación de delitos contra la salubridad pública) y la justicia administrativa (a través del conocimiento del recurso contencioso-administrativo que pretenda impugnar un acto administrativo dictado en contravención al derecho ambiental). Cfr. BRAÑES BALLESTEROS, R., "El acceso...” cit., pp. 55-85. 
asunto, o bien el sistema mixto, donde para acceder al órgano judicial es requisito previo haber agotado la vía administrativa ${ }^{13}$.

En derecho comparado también es posible apreciar la existencia de tribunales ambientales con competencia exclusiva para el conocimiento de causas ambientales, así como la utilización de mecanismos alternativos o colaborativos que no comprenden una revisión jurisdiccional del conflicto ambiental, sino sistemas de negociación que tienen como objeto acercar las posiciones de las partes en conflicto para que sean ellas mismas quienes determinen la forma de resolverlo ${ }^{14}$.

No resulta posible, además de ser innecesario, determinar a priori cuál de estos mecanismos es el más idóneo para propender a la implementación del derecho de acceso a la justicia ambiental; ello variará dependiendo de la conformación de cada ordenamiento jurídico y de la idiosincrasia de la sociedad. En consecuencia, habrá que realizar un análisis exhaustivo acerca de la aplicación del mecanismo elegido por un determinado ordenamiento jurídico para poder establecer su eficiencia y eficacia en el cumplimiento del objetivo perseguido por el derecho a vivir en un medio ambiente sano.

Cualquiera que sea el mecanismo que determine el legislador, este se considerará idóneo si proporciona una solución imparcial, equitativa, completa y expedita mediante el establecimiento de procedimientos que prevengan eficazmente los daños ambientales $\mathrm{y}$, para los casos en los que estos lleguen a producirse, aseguren una rápida y adecuada reparación ${ }^{15}$.

\footnotetext{
${ }^{13}$ En España, por ejemplo, aparte de los mecanismos de reclamación administrativos, se destaca el sistema judicial, que opera de la siguiente manera: a través de la vía constitucional, mediante el recurso de amparo; a través de la vía civil, mediante la aplicación del "Derecho de inmisiones", por el cual se pueden ejercer las acciones de cesación y de responsabilidad por actividades molestas o nocivas encuadradas dentro de las relaciones de vecindad; a través de la vía penal, mediante el ejercicio de la acción por los delitos ambientales tipificados en los artículos 325 y siguientes del Código Penal; y a través de la vía contencioso-administrativa, que es la más habitual. Asimismo, se han implementado vías que corresponden al derecho internacional, como el uso del recurso ante el Tribunal Europeo de Derechos Humanos por vulneración del Convenio de Roma de 1950 o el acceso a la vía judicial comunitaria mediante la posibilidad de queja ante la Comisión Europea, para que esta plantee a su vez la correspondiente acción ante el Tribunal de Luxemburgo por incumplimiento del Estado. Cfr. RUIZ DE APODACA ESPINOSA, A., "Nuevas..." cit., pp. 188 y ss.

${ }^{14}$ Cfr. PRIEUR, M., Complaints and appeals in the area of environment on the member states of the European Union, Commission of the European Community, DGXI, European Council on Environmental Law / European Environmental Law Association, marzo de 1998, p. 15.

${ }^{15}$ Véase el preámbulo de la Ley 26/2007, de 23 de octubre, de Responsabilidad Medioambiental.
} 
En todos aquellos ordenamientos donde no se prevean mecanismos adecuados para resolver conflictos ambientales que cumplan las mencionadas características, nos encontraremos frente a una barrera para la implementación del derecho de acceso a la justicia ambiental.

\subsection{Legitimación activa}

La legitimación activa en materia ambiental constituye tal vez el aspecto del derecho de acceso a la justicia que ha suscitado mayores controversias en doctrina y jurisprudencia, tanto a nivel nacional como internacional. En esencia, la controversia se centra en determinar si la legitimación puede existir con independencia de la titularidad de los derechos e intereses individuales legítimos.

De manera general, la cuestión de la legitimación activa frente a los tribunales de justicia se ha resuelto a la usanza decimonónica: podrá reclamar un derecho subjetivo vulnerado únicamente la persona afectada y respaldada en su interés individual legítimo. No obstante, esta fórmula "de marcado matiz individualista falla actualmente ante las exigencias de una sociedad industrial basada en el consumo masivo y los conflictos de naturaleza intrínsecamente colectiva"16. Es lo que sucede con el derecho a vivir en un medio ambiente sano; una vez vulnerado, produce, por una parte, un atentado a intereses públicos (protección de la naturaleza) y, por otra, un atentado a intereses privados (protección a la salud, a la propiedad), intereses todos ellos que pertenecen a personas indeterminadas e indeterminables, por lo que también se les denomina "intereses difusos" ${ }^{17}$ que pertenecen a la colectividad.

Advirtiendo esta situación, la doctrina ha reconocido la necesidad de garantizar la protección procesal del interés colectivo a un medio ambiente sano, existiendo un

\footnotetext{
${ }^{16}$ GOMIS CATALÁ, L., Responsabilidad por daños al medio ambiente, Aranzadi, Pamplona, 1998, p. 198.

${ }^{17}$ Conforme a la "teoría de los intereses difusos", De la Barra Gili señala que existen determinados derechos o intereses legítimos que, por su naturaleza, quedan sustraídos en su protección al ámbito dispositivo de poder de un sujeto aislado que ha sufrido un menoscabo en su derecho o interés, correspondiéndole a entidades de derecho público, asociaciones privadas o colectividades no organizadas la titularidad en el derecho o en su ejercicio, puesto que existiría un interés global que superaría el ámbito estrictamente individual del sujeto. Es decir, se trata de intereses comúnmente compartidos por muchas personas, entre las cuales no existe relación jurídica alguna, pero que se ven igualmente afectadas por la lesión de un determinado bien. Véase DE LA BARRA GILI, F., "Responsabilidad extracontractual por daño ambiental: El problema de la legitimación activa", Revista Chilena de Derecho, núm. 29, tomo II, 2002, p. 378.
} 
consenso impuesto por un ideal de justicia que implanta la superación de los mecanismos clásicos de legitimación para dar paso a nuevos métodos basados en los nuevos conceptos de "garantismo social o colectivo" como son las acciones populares o las acciones colectivas ejercidas por organizaciones no gubernamentales (ONG) de defensa del medio ambiente ${ }^{18}$. Hasta ahí llega el consenso, señala la jurista Lucía Gomis Catalá, quien agrega que "en el Legislador y en los Tribunales está el disenso"19.

En consecuencia, "cuando un sujeto pasa a ser considerado miembro de una colectividad en la que se comparten intereses colectivos, a la vez ajenos y propios, pero comunes, la legitimación y por tanto, la protección jurisdiccional de tales intereses colectivos encuentra serios obstáculos" 20 .

Finalmente, considerando que la capacidad de actuar ante los tribunales es esencial para la efectividad de los derechos ambientales ${ }^{21}$, resulta imprescindible otorgar una legitimación activa amplia y suficiente para la defensa de los intereses difusos, especialmente para el caso de los ordenamientos jurídicos que contemplan un reconocimiento constitucional del derecho a vivir en un medio ambiente sano ${ }^{22}$.

${ }^{18}$ Cfr. GOMIS CATALÁ, L., "La ley de responsabilidad medioambiental en el marco del derecho de la Unión Europea", Lozano Cutanda, B. (coord.), Comentarios a la Ley de responsabilidad medioambiental. Ley 26/2007, de 23 de octubre, Thomson Civitas, Pamplona, 2008, p. 125.

${ }^{19}$ GOMIS CATALÁ, L., Responsabilidad... cit., p. 209. No obstante, en el derecho comparado español, aun cuando no se otorgue la pretendida legitimación activa amplia de forma generalizada, es indiscutible que se ha avanzado mucho a ese respecto. La Ley 27/2006, de 18 de julio, por la que se regulan los derechos de acceso a la información, de participación pública y de acceso a la justicia en materia de medio ambiente, establece, en sus artículos 22 y 23 , una acción popular para asuntos ambientales, otorgando amplia legitimación activa a las ONG que reúnan ciertas características. Cfr. RUIZ DE APODACA ESPINOSA, A., "Nuevas..." cit., p. 197.

${ }^{20}$ RAZQUIN LIZARRAGA, J. A. y RUIZ DE APODACA ESPINOSA, Á., Información ... cit., p. 379, siguiendo a HUELÍN MARTÍNEZ DE VELASCO, J., "La protección jurisdiccional del medio ambiente", Protección Administrativa del Medio Ambiente, núm. 28, Colección Cuadernos de Derecho Judicial, 1994, p. 213.

${ }^{21}$ JARIA I MANZANO, J., "El fundamento..." cit., p. 143, siguiendo a BRUCH, C., CROCKER, W. y VANARSDALE, C., "Constitutional environmental law: Giving force to fundamentals principles in Africa", Columbia Journal of Environmental Law, núm. 26, tomo I, 2001, p. 179.

${ }^{22}$ Cfr. PEÑALVER I CABRÉ, A., "Novedades en el acceso a la justicia y a la tutela administrativa en asuntos medioambientales", Pigrau Solé, A. (dir.), Acceso a la información, participación pública y acceso a la justicia en materia de medio ambiente: diez años del Convenio de Aarhus, Atelier, Barcelona, 2008, p. 376, y JORDANO FRAGA, J., La protección del derecho a un medio ambiente adecuado, Bosch, Barcelona, 1995, pp. 80-81, entre otros. 


\subsection{Condiciones de igualdad en el acceso a la justicia ambiental}

Si bien la dogmática jurídica atiende a diversas aristas para caracterizar el principio general de igualdad en los procedimientos, a efectos de este análisis únicamente nos centraremos en aquel aspecto relativo a la aplicación práctica y concreta de las normas procesales que tienen por finalidad proporcionar iguales medios a las partes para defender en el proceso sus respectivas posiciones, considerando que intrínseca y funcionalmente estas se encuentran en un plano de desigualdad ${ }^{23}$. Esta igualdad se logra mediante el reconocimiento del derecho de acción, con la simplificación de los procedimientos y mediante el establecimiento de fórmulas económicas destinadas a poner a la parte socialmente más débil en condiciones de paridad ${ }^{24}$.

Con relación al aspecto material de este principio de igualdad, no resulta novedoso afirmar que, ante un conflicto ambiental, normalmente hay una relación desigual entre la parte demandante, con una capacidad económica reducida (generalmente, ONG de defensa del medio ambiente, asociaciones sin ánimo de lucro, grupos de vecinos...), y la parte demandada (generalmente, Administración o empresas privadas contaminantes). Ello constituye un severo obstáculo al derecho de acceso a la justicia ambiental, toda vez que supone un elemento de disuasión para la ciudadanía a la hora de plantearse recurrir a los tribunales en defensa de su derecho a vivir en un medio ambiente libre de contaminación ${ }^{25}$.

Con la finalidad de superar esta barrera, el Convenio de Aarhus establece la necesidad de que los Estados implementen, en sus ordenamientos jurídicos, mecanismos encaminados a eliminar o reducir los obstáculos financieros que impidan el acceso a la justicia ambiental ${ }^{26}$.

El cumplimiento efectivo de este elemento implicaría, entre otros aspectos: a) una ampliación del beneficio de justicia gratuita para las asociaciones que persigan la

${ }^{23}$ Cfr. BENÍTEZ RAMÍREZ, E., "Principios procesales relativos a las partes", Revista Chilena de Derecho, núm. 34, tomo III, 2007, pp. 591-593.

${ }^{24}$ Cfr. MONTERO AROCA, J. et ál., Derecho Jurisdiccional, parte general, Tirant Lo Blanch, tomo I, 16. ${ }^{\mathrm{a}}$ ed., Valencia, 2008, p. 342.

${ }^{25}$ Cfr. RAZQUIN LIZARRAGA, J. A. y RUIZ DE APODACA ESPINOSA, Á., Información... cit. pp. 406 y ss., y PEÑALVER I CABRÉ, A., "Novedades...” cit., pp. 384 y ss.

${ }^{26}$ Véase el artículo 9.5 del Convenio de Aarhus de 25 de junio de 1998, sobre el acceso a la información, la participación del público en la toma de decisiones y el acceso a la justicia en materia de medio ambiente, Aarhus (Dinamarca). 
protección del medio ambiente; b) un modelo de condena en costas de corte redistributivo y compensador de la tarea de agentes sociales de defensa del medio ambiente; c) el reembolso de los gastos de los ciudadanos por el ejercicio de acciones ante la pasividad de la Administración; d) la inviabilidad de las fianzas o cauciones; y e) la eliminación de toda tasa judicial para ONG y ciudadanos que persigan la protección del medio ambiente ${ }^{27}$.

\section{EL DERECHO DE ACCESO A LA JUSTICIA AMBIENTAL EN CHILE}

Desde la década pasada, cierto sector de la doctrina ${ }^{28}$ comenzó a indagar, de manera más acuciosa, el tema de la implementación del derecho de acceso a la justicia ambiental en Chile, siguiendo los lineamientos establecidos por el derecho internacional y comparado.

En 2005, mediante el esfuerzo conjunto de una serie de investigadores y académicos ${ }^{29}$, se logró presentar un panorama general acerca de la situación del acceso a la información, la participación y la justicia ambiental en $\mathrm{Chile}^{30}$.

Este panorama se mantuvo prácticamente intacto hasta el año pasado, cuando se publicó la Ley 20.600/2012, de 28 de junio, que creaba los tribunales ambientales. Esta norma viene a suponer un cambio en el desarrollo del derecho de acceso a la justicia en materia

\footnotetext{
${ }^{27}$ Cfr. PEÑALVER I CABRÉ, A., "Novedades..." cit., p. 385. En el derecho comparado español, en el intento de evitar el efecto que genera este tipo de obstáculo, se ha dispuesto en la Ley 27/2006, de 18 de julio, por la que se regulan los derechos de acceso a la información, de participación pública y de acceso a la justicia en materia de medio ambiente, el beneficio de justicia gratuita a las ONG ambientales en los términos previstos en la Ley 1/1996, de 10 de enero, de Asistencia Jurídica Gratuita. Cfr. RUIZ DE APODACA ESPINOSA, A., "Nuevas..." cit., p. 213.

${ }^{28}$ Durante el año 2004, un grupo de juristas adscritos al Centro de Derecho Ambiental de la Facultad de Derecho de la Universidad de Chile realizó el primer proyecto piloto destinado a determinar la situación del acceso a la justicia ambiental en Chile mediante la aplicación de una metodología establecida por la organización The Access Initiative. Véase: THE ACCESS INITIATIVE (2012, 20 de abril). Recuperado el 20 de abril de 2012, de <http://www.accessinitiative.org/poverty/node/323>.

${ }^{29}$ Este mismo esfuerzo académico ha sido realizado por juristas de distintos lugares del orbe. En el caso de España, la Asociación para la Justicia Ambiental (AJA), a través de un convenio de colaboración firmado con la Fundación Biodiversidad, realizó un estudio sobre el acceso a la justicia y la aplicación del Convenio de Aarhus en dicho país. Cfr. MARRACO ESPINÓS, J. M., "Reflexiones sobre las dificultades del acceso a la justicia ambiental desde la perspectiva del abogado", Pigrau Solé, A. y Casado Casado, L. (dirs.), Derecho ambiental y transformaciones de la actividad de las administraciones públicas, Barcelona, Atelier, 2010, p. 223 y ss.

${ }^{30}$ Para estos efectos, se formó una coalición constituida por Corporación Participa, Codesosur-Sinergias Rides y el Centro de Derecho Ambiental de la Facultad de Derecho de la Universidad de Chile. Véase: AA. VV., Acceso a la información, participación y justicia en temas ambientales en Chile: ¿Cuánto hemos avanzado?, Resumen ejecutivo, The Access Initiative, Santiago de Chile, 2005.
} 
ambiental y permite analizarlo desde un punto de vista distinto, abriendo, en consecuencia, una nueva etapa para este pilar de acceso en el ordenamiento jurídico ambiental chileno.

A continuación, verificaremos la implementación del derecho de acceso a la justicia ambiental en estas dos etapas distintas. Utilizaremos, como herramienta de análisis, los elementos mencionados previamente, con la finalidad de vislumbrar las virtudes y los obstáculos de cada una de estas fases.

\section{La implementación del derecho de acceso a la justicia en materia ambiental en}

\section{Chile antes de la instauración de los tribunales ambientales}

El derecho de acceso a la justicia ambiental en Chile se ha verificado principalmente por la acción de protección establecida en la Constitución Política de la República de Chile $^{31}$ y las acciones que persiguen la responsabilidad extracontractual por daño ambiental de la Ley 19.300/1994, de 9 de marzo, sobre bases del medio ambiente ${ }^{32}$ : la acción indemnizatoria y la acción ambiental propiamente tal, que persigue la reparación del medio ambiente dañado ${ }^{33}$.

Con el objeto de vislumbrar el nivel de implementación del derecho de acceso a la justicia en Chile a través de estas acciones, procederemos a aplicar a continuación, en calidad de instrumento de análisis empírico, los elementos generales a que se ha hecho referencia anteriormente.

\footnotetext{
${ }^{31}$ Véase el artículo 20, inciso 2. ${ }^{\circ}$ de la Constitución Política de la República de Chile, reformado por la Ley 20.050/2005, de 26 agosto: "Procederá, también, el recurso de protección en el caso del $\mathrm{n}^{\circ} 8^{\circ}$ del artículo 19, cuando el derecho a vivir en un medio ambiente libre de contaminación sea afectado por un acto u omisión ilegal imputable a una autoridad o persona determinada".

${ }^{32}$ Véase el artículo 53.1 de la Ley $\mathrm{N}^{\circ} 19.300 / 1994$, de 9 de marzo, sobre bases del medio ambiente, modificada por la Ley $\mathrm{N}^{\mathrm{o}} 20.417 / 2010$, de 26 enero, y por la Ley $\mathrm{N}^{\mathrm{o}} 20.473 / 2010$, de 13 noviembre: "Producido daño ambiental, se concede acción para obtener la reparación del medio ambiente dañado, lo que no obsta al ejercicio de la acción indemnizatoria ordinaria por el directamente afectado".

${ }^{33}$ Si bien existen otras vías para ejercer el derecho de acceso a la justicia ambiental, como es el caso del recurso de nulidad de derecho público, el recurso de reclamación del artículo 50 de la Ley $\mathrm{N}^{\circ}$ 19.300/1994, el recurso de amparo económico y las acciones penales destinadas a perseguir crímenes y simples delitos contra la salud pública o delitos de propagación de enfermedad animal o plaga vegetal, entre otras vías contenidas en leyes especiales, dichos mecanismos no serán tratados en el presente trabajo toda vez que su incidencia en la implementación del derecho de acceso a la justicia ambiental es escasa y relativamente nula.
} 


\subsection{Desarrollo y aplicación de la normativa ambiental en Chile}

El ámbito de ejercicio de estas acciones se encuadra dentro de la normativa ambiental existente en Chile, y tal como sucede en todo el orbe, esta se encuentra aún en una etapa inicial de desarrollo. No obstante, es imperativo destacar que el derecho a vivir en un medio ambiente libre de contaminación se encuentra reconocido a nivel constitucional en calidad de derecho fundamental, configurando un "gravamen ambiental" sobre el ejercicio de los derechos y las libertades constitucionales por condicionar sus fines a la protección de un medio ambiente sano como manifestación del bien común ${ }^{34}$.

Aun cuando la producción de la normativa ambiental ha sido constante en Chile, es posible detectar que la labor legislativa y administrativa no ha regulado las materias de manera uniforme, entendiendo el derecho ambiental como una disciplina global e integradora. Se ha atendido más bien a criterios sectoriales, con lo cual se ha generado una normativa dispersa e inorgánica, lo que dificulta su cumplimiento y fiscalización.

Advirtiendo esta debilidad del sistema, el legislador dicta en el año 1994 la Ley $\mathrm{N}^{\mathrm{o}}$ 19.300 sobre bases generales de medio ambiente en el intento de uniformar el ordenamiento jurídico ambiental. No obstante, a pesar de este esfuerzo, el modelo de fiscalización resultó ineficaz, puesto que continuó basándose en un enfoque sectorial ${ }^{35}$. Lo propio sucedió con el modelo sancionatorio, ya que carecía de disuasión suficiente para que cumpliera una finalidad preventiva ${ }^{36}$.

Si a todo ello agregamos que la participación ciudadana en la toma de estas decisiones ambientales ha sido tan escasa como la información a que se ha tenido acceso, es posible concluir que este desarrollo normativo no significó el reflejo del consenso social en la determinación del modelo de desarrollo deseado por la sociedad en su conjunto.

${ }^{34}$ Cfr. DOUGNAC RODRÍGUEZ, F., "La Garantía del No8 del artículo 19 de la Constitución como Derecho Humano", Primeras Jornadas Nacionales de Derecho Ambiental, 28 y 29 de noviembre de 2001, Santiago de Chile, CONAMA, CDA, Universidad de Chile, 2003, pp. 240-262.

35 Actualmente, mediante la Ley 20.417/2010, que regula la nueva institucionalidad ambiental, se ha creado un nuevo servicio público cuya misión fundamental es la de fiscalizar el cumplimiento de la normativa ambiental: la Superintendencia de Medio Ambiente. Señala la norma que este organismo comenzará a ejercer sus funciones una vez que se inicie el funcionamiento de los tribunales ambientales. (Véase el artículo segundo y el artículo noveno de la Ley 20.417/2010, de 12 de enero, que crea el Ministerio, el Servicio de Evaluación Ambiental y la Superintendencia del Medio Ambiente).

${ }^{36}$ Cfr. PROGRAMA DE NACIONES UNIDAS PARA EL MEDIO AMBIENTE (2012, 20 de abril), Quinto Programa Regional de Capacitación en Derecho y Políticas Ambientales. País: Chile. Recuperado el 20 de abril de 2013, de <http://www.pnuma.org/deramb/documentos/legislacionporpaises/CHILE.pdf>. 
Finalmente, fracasa la aplicación voluntaria de la normativa ambiental, se generan conflictos ambientales y toman relevancia los órganos judiciales llamados a conocer y resolver dichos conflictos.

\subsection{Autoridades idóneas para conocer los asuntos ambientales en Chile}

Los tribunales de justicia competentes para conocer tanto de la acción de protección como de las acciones que persiguen la responsabilidad extracontractual ambiental se rigen por ciertos principios que garantizan su actuación en un marco de legalidad, independencia, imparcialidad, doble instancia y responsabilidad. En este sentido, existe una concordancia respecto de las directrices establecidas por el Convenio de Aarhus para la implementación del derecho de acceso a la justicia ambiental ${ }^{37}$.

Es competente para conocer de la acción de protección la Corte de Apelaciones respectiva, cuya resolución es apelable ante la Corte Suprema ${ }^{38}$. En el caso de las acciones destinadas a perseguir la responsabilidad extracontractual por daño ambiental, tanto la indemnizatoria como la ambiental propiamente tal eran conocidas, bajo el antiguo sistema, por los juzgados de letras en lo civil del lugar en que se hubiera originado el hecho que causa el daño o del domicilio del afectado ${ }^{39}$. Las resoluciones que hubiesen dictado en el ámbito de su competencia también eran apelables ante la Corte de Apelaciones correspondiente ${ }^{40}$.

Tanto los ministros integrantes de la Corte de Apelaciones como el juez de letras en lo civil, para ejercer como tales, han debido cumplir todos los requisitos de idoneidad que establece la ley para ingresar en la carrera funcionaria del poder judicial. Sin embargo, en ningún caso se les exige tener el conocimiento técnico-científico suficiente para conocer cada causa que se les plantea, todo lo cual se resuelve mediante la aportación de las pruebas correspondientes, especialmente a través de los informes periciales.

\footnotetext{
${ }^{37}$ Véase el artículo 9.1 del Convenio de Aarhus de 25 de junio de 1998, sobre el acceso a la información, la participación del público en la toma de decisiones y el acceso a la justicia en materia de medio ambiente.

${ }^{38}$ Véase el Auto Acordado de la Corte Suprema de 24 de junio de 1992 sobre tramitación y fallo del recurso de protección de garantías constitucionales.

${ }^{39}$ Véase el antiguo artículo 60 de la Ley 19.300/1994, de 9 de marzo, sobre bases generales del medio ambiente (modificado por la Ley 20.417/2010, de 12 de enero, que crea el Ministerio, el Servicio de Evaluación Ambiental y la Superintendencia del Medio Ambiente).

${ }^{40}$ Véase el artículo 62.2 de la Ley 19.300/1994, de 9 de marzo, sobre bases generales del medio ambiente.
} 
En definitiva, no nos encontramos frente a autoridades especializadas para la resolución de conflictos jurídicos de naturaleza ambiental, pudiendo apreciarse, en consecuencia y a la luz de los elementos planteados, un obstáculo para la implementación del derecho de acceso a la justicia ambiental.

\subsection{Mecanismos de resolución de conflictos ambientales en Chile}

Para determinar si los mencionados tribunales conocen de estas acciones de forma completa y expedita que asegure una rápida y adecuada reparación, es menester distinguir el procedimiento establecido para uno y otro caso.

Respecto a la acción de protección ambiental, su procedimiento ha sido establecido por la Corte Suprema, en virtud de sus facultades económicas, en el Auto Acordado sobre tramitación y fallo del recurso de protección de las garantías constitucionales de 27 de junio de 1992, donde explícitamente señala que el propósito de dicha acción es el de "obtener una mayor expedición en su tramitación y despacho final, como, asimismo para conferir a los agraviados mayor amplitud y facilidad para la defensa de las garantías constitucionales"41.

Considerando que el procedimiento está exento de mayores formalidades de comparecencia en el juicio, que se le otorga prioridad en su conocimiento y que, atendida la conveniencia, el tribunal puede decretar una orden de no innovar, podemos afirmar que cumple con el elemento de celeridad, necesario para la efectiva implementación del derecho de acceso a la justicia ambiental.

En la práctica, con anterioridad a la entrada en vigor de la Ley 19.300/1994, de 9 de marzo, sobre bases generales del medio ambiente, la acción de protección era una herramienta eficaz en el ejercicio del derecho de acceso a la justicia ambiental. Los tribunales, al considerar que se trataba de una materia inorgánicamente regulada, "solían tener un criterio de mayor latitud para avocarse al conocimiento de los problemas ambientales y resolverlos". A partir de la creación de la Comisión Nacional del Medio Ambiente (CONAMA) ${ }^{42}$ como un organismo especializado, "los tribunales de justicia

\footnotetext{
${ }^{41}$ Véase la exposición de motivos del Auto Acordado de la Corte Suprema de 24 de junio de 1992 sobre tramitación y fallo del recurso de protección de garantías constitucionales.

${ }^{42}$ La actualmente extinta Comisión Nacional del Medio Ambiente era un servicio público funcionalmente descentralizado, con personalidad jurídica y patrimonio propio, sometido a la supervigilancia del presidente de la República a través del Ministerio Secretaría General de la Presidencia. A esta
} 
se sintieron liberados de su obligación de velar por el medio ambiente", rechazando así, en un $90 \%$, los recursos de protección que antes se acogían. Actualmente, los tribunales únicamente revisan si la decisión de la autoridad ambiental ha sido formalmente dictada, evitando pronunciarse sobre el fondo de los asuntos sometidos a su consideración, lo que indudablemente representa un retroceso en el ámbito del derecho de acceso a la justicia ambiental en Chile $^{43}$.

A propósito de las normas sobre el procedimiento a través del cual se habrán de conocer las acciones que persiguen la responsabilidad extracontractual por daño ambiental, estas se encontraban contenidas en el párrafo $2 .^{\circ}$ del título $\mathrm{V}$ de la Ley 19.300/1994, estableciendo, en su artículo 61, que "se tramitarán conforme al procedimiento sumario" 44 . Se trata de un procedimiento regulado en el Código de Procedimiento Civil $^{45}$ que se aplica a toda acción que por su naturaleza requiere una tramitación rápida para que sea eficaz. Sin embargo, la celeridad pretendida lo es únicamente en apariencia, tal como lo señaló en su momento el diputado Hernán Bosselin durante la discusión legislativa respecto de la Ley 19.300/1994, cuando expuso que "se habla de procedimiento sumario, y se piensa que es rápido y expedito, porque la voz 'sumario' así lo indica en su sentido natural y obvio; pero si uno va a la lectura del texto legal, llega a la piramidal conclusión de que será un juicio muy complejo"46.

En efecto, consideramos que, aun cuando el legislador tiene la intención de dotar al procedimiento de celeridad por tratarse de un elemento indispensable para el adecuado ejercicio del derecho de acceso a la justicia ambiental, ello no logra plasmarse en la práctica, resultando, por lo tanto, ineficaz para abordar las materias o pretensiones

administración le correspondía, entre otras atribuciones, proponer las políticas ambientales, informar sobre el cumplimiento y la aplicación de la legislación vigente en materia ambiental, actuar como órgano de consulta, análisis, comunicación y coordinación en materias relacionadas con el medio ambiente, mantener un sistema de información ambiental y administrar el sistema de evaluación de impacto ambiental. (Conforme a la antigua redacción de los artículos 69 y 70 de la Ley 19.300/1994, de 9 de marzo, sobre bases generales del medio ambiente). Actualmente esas y otras funciones corresponden al Ministerio de Medio Ambiente, que surgió a través de la Ley 20.417/2010, de 12 de enero, que crea el Ministerio, el Servicio de Evaluación Ambiental y la Superintendencia del Medio Ambiente.

${ }^{43}$ Cfr. entrevista realizada al jurista Dougnac Rodríguez, Premio Nacional de Medio Ambiente 2003, sobre el acceso a la justicia ambiental en: GUTIÉRREZ SAEZ, M., El Acceso a la Justicia Ambiental en Chile: Un desafio pendiente, Memoria (Grado en Ciencias Jurídicas y Sociales), Universidad de Chile, Facultad de Derecho, Santiago de Chile, 2005. (Anexo).

${ }^{44}$ El artículo mencionado fue derogado por la Ley 20.417/2010, de 12 de enero, que crea el Ministerio, el Servicio de Evaluación Ambiental y la Superintendencia del Medio Ambiente.

${ }^{45}$ Véanse los artículos 680 a 692 del título XI del Código de Procedimiento Civil.

${ }^{46}$ Cámara de Diputados. Legislatura 327, Sesión 25. Fecha 4 de enero, 1994. Discusión general. 
sometidas a conocimiento de los tribunales de justicia mediante las referidas acciones ${ }^{47}$. En tal sentido, es posible indicar una serie de obstáculos que derivan indefectiblemente en la necesidad de un lato conocimiento del asunto, principalmente porque el sistema de responsabilidad extracontractual que se consagra como regla general es el subjetivo por culpa o negligencia ${ }^{48}$, razón por la cual se requiere una extensa e intensa actividad en su etapa probatoria, correspondiéndole la carga de la prueba a quien alega la responsabilidad $^{49}$.

En definitiva, podemos concluir que el ordenamiento jurídico tal como estaba conformado no cumplía con el elemento de celeridad que se requiere para la implementación del derecho de acceso a la justicia ambiental.

\subsection{Legitimación activa en los procesos sobre medio ambiente en Chile}

La actual normativa que contempla las acciones de protección y la antigua normativa por la cual se perseguía la responsabilidad ambiental son también posibles de ser analizadas con respecto al elemento de acceso a la justicia ambiental que ha recibido mayor atención por parte de la doctrina: la legitimación activa.

Si bien la Ley 19.300/1994, de 9 de marzo, sobre bases generales del medio ambiente, establece las dos acciones que tienen por objeto perseguir la responsabilidad por daño ambiental, únicamente regula la legitimación activa respecto a la acción ambiental destinada a obtener la reparación del medio ambiente dañado. Para determinar la persona del legitimado activo de la acción indemnizatoria, habrá que aplicar

\footnotetext{
${ }^{47}$ Cfr. PROGRAmA DE NACIONES UNIDAS PARA EL MEDIO AMBIENTE, Quinto Programa Regional de Capacitación en Derecho y Políticas Ambientales. País: Chile [en línea] cit.

${ }^{48}$ Véase el artículo 51 de la Ley 19.300/1994, de 9 de marzo, sobre bases generales del medio ambiente: "Todo el que culposa o dolosamente cause daño ambiental, responderá del mismo en conformidad a la presente ley. No obstante, las normas sobre responsabilidad por daño al medio ambiente contenidas en leyes especiales prevalecerán sobre las de la presente ley. Sin perjuicio de lo anterior, en lo no previsto por esta ley o por leyes especiales, se aplicarán las disposiciones del Título XXXV del Libro IV del Código Civil”.

${ }^{49}$ En este sentido, expresa el autor Fernández Bitterlich, con quien coincidimos, que "el peso de la prueba debería recaer sobre quien va a ejecutar o está ejecutando un acto que pueda producir deterioro ambiental. Es él quien tiene que formar evidencia ante la sociedad de que sus acciones no dañarán a la naturaleza, que no destruirán el ambiente, y no al revés como sucede en la actualidad". FERNÁNDEZ BITTERLICH, P., Manual de Derecho Ambiental Chileno, Editorial Jurídica de Chile, 2. a ed., Santiago de Chile, 2004, p. 144.
} 
supletoriamente las reglas de la responsabilidad civil extracontractual correspondientes $^{50}$.

Conforme a las normas del derecho civil, esta acción indemnizatoria, aun cuando derivada de la generación de un daño en la esfera ambiental, tiene por objeto resarcir el perjuicio producido exclusivamente en el ámbito individual de una persona cuando repercute en su patrimonio o en su integridad física o psíquica. En consecuencia, el bien jurídico inmediatamente protegido será el derecho de naturaleza individual que ha sido vulnerado (derecho a la vida, a la salud o a la propiedad de una persona) y el legitimado para ejercitar la acción indemnizatoria, aquella persona cuyo derecho o interés individual ha sido directamente afectado, restando al medio ambiente únicamente una "protección mediata, en la medida que el sujeto pasivo del daño la solicitara, como medida necesaria para poner fin a la lesión que le afecta, que se pusiera término a la actividad generadora del mismo"

Respecto a la acción ambiental, dispone el artículo 54 de la Ley 19.300/1994, de 9 de marzo, sobre bases generales del medio ambiente, que son sus titulares, con el solo objeto de obtener la reparación del medio ambiente dañado, las personas naturales o jurídicas, públicas o privadas, que hayan sufrido el daño o perjuicio, las municipalidades, por los hechos acaecidos en sus respectivas comunas, y el Estado, por intermedio del Consejo de Defensa del Estado.

Se concede titularidad activa, en primer término, para el ejercicio de esta acción a personas "que hayan sufrido el daño", siguiendo la tesis mayoritaria propia de la responsabilidad civil extracontractual, que considera que la titularidad de la acción le corresponde únicamente a la persona que ha sido individualmente lesionada en su derecho, y que se respalda en el principio "donde no hay interés no hay acción"

Sin embargo, esta norma no ha estado exenta de discusión en doctrina. Al disponer, por una parte, que tiene por objeto "la reparación del medio ambiente dañado" y, por otra, que legitima para el ejercicio de la acción "a las personas que hayan sufrido el daño", a todas luces resulta confusa, tal como lo ha señalado el jurista Enrique Barros Bourie,

\footnotetext{
${ }^{50}$ Tal como lo dispone el inciso 2. ${ }^{\circ}$ del artículo 51 de la Ley 19.300/1994, de 9 de marzo, sobre bases generales del medio ambiente.

${ }^{51}$ DE LA BARRA GILI, F., "Responsabilidad...” cit., p. 390.

${ }^{52}$ Ibíd.
} 
quien estima inverosímil la "hipótesis de un daño ambiental que opere directamente sobre la persona de la víctima" ${ }^{, 53}$. Esta acción pretende la reparación del daño causado al medio ambiente y no al daño causado a una persona concreta en su interés legítimo, situación para la cual la norma dispone la acción indemnizatoria ordinaria ${ }^{54}$.

Con el objeto de salvar esta problemática suscitada por la redacción de la norma, algunos autores estiman que esta debe ser interpretada considerando al medio ambiente como un bien de interés colectivo o difuso. En consecuencia, ha de ampliarse la legitimación activa en beneficio del interés difuso y no del interés particular ${ }^{55}$.

La norma también admite, como legitimados activos para interponer esta acción, a las personas jurídicas, cuestión que también ha sido discutida en doctrina, sea a favor o en contra de ampliar dicha legitimación. Los que se encuentran en contra, además de basarse en el mismo principio de que la acción tiene como fin salvaguardar los intereses individuales, agregan que no es posible atentar contra derechos que son eminentemente humanos respecto de las personas jurídicas.

Esa postura es rebatida por el sector de la doctrina que considera que "la sola circunstancia de que una norma se halle enlazada con los atributos humanos, no es suficiente para excluir su aplicación a las personas jurídicas" ${ }^{, 56}$. La norma referida podrá incluir eventualmente a las personas jurídicas cuando sea susceptible de conciliar su finalidad respecto de estas. Si consideramos que el principal objeto que persigue la Ley general de bases del medio ambiente consiste en la protección de la naturaleza para que el ser humano pueda desarrollarse íntegramente, entonces ciertas personas jurídicas podrán ser legitimados activos de la acción cuando cumplan con finalidad similar, como

\footnotetext{
${ }^{53}$ BARROS BOURIE, E., "Responsabilidad civil en materia de medio ambiente", Derecho del Medio Ambiente, Editorial Jurídica Conosur Ltda., Fundación Facultad de Derecho, Universidad de Chile, Santiago de Chile, 1998, p. 55.

${ }^{54}$ Cfr. VALENZUELA FUENZALIDA, R., "La responsabilidad civil por daño ambiental", Derecho del Medio Ambiente, Editorial Jurídica Conosur Ltda., Fundación Facultad de Derecho, Universidad de Chile, Santiago de Chile, 1998, p. 67.

${ }^{55}$ Cfr. BORDALÍ SALAMANCA, A., "Titularidad y legitimación activa sobre el ambiente en el derecho chileno", Revista de Derecho de la Universidad Austral de Chile, núm. 9, tomo I, diciembre de 1998, pp. 43-64.

${ }^{56}$ LYON PUELMA, A., Teoría de la Personalidad, Ediciones Universidad Católica de Chile, Santiago de Chile, 1993, p. 161.
} 
sucede respecto de organizaciones no gubernamentales que se crean con el objetivo de proteger y conservar el medio ambiente ${ }^{57}$.

Esta discusión continúa aún vigente por cuanto no es una materia que se encuentre definida ni en doctrina ni en jurisprudencia. En el intertanto, consideramos que la regla general determina que la legitimación activa respecto de personas jurídicas para ejercer la acción ambiental ha resultado ser, más bien, restringida.

Un aspecto de la norma que merece destaque es que otorga legitimación activa para el ejercicio de la acción ambiental al Estado, a través del Consejo de Defensa del Estado, y a las municipalidades respecto de los hechos acaecidos en sus respectivas comunas. Ello denota que el legislador es consciente de que los daños ocasionados al medio ambiente inevitablemente repercuten en una colectividad indeterminada, y quién mejor para representar a esta colectividad que un ente que los congregue a todos como es la municipalidad y, más propiamente, el Estado ${ }^{58}$.

Con relación a la acción de protección, la determinación del legitimado activo tampoco se encuentra claramente definida. Cierto sector sostiene que solo puede ser deducida por quien sea afectado personalmente en su derecho a vivir en un medio ambiente libre de contaminación, debiendo individualizarse claramente la persona del recurrente por cuanto tiene como objetivo resguardar un derecho subjetivo individual ${ }^{59}$.

A pesar de dicha postura, consideramos de suma importancia resaltar la jurisprudencia que amplió la legitimación activa para el ejercicio de la acción de protección al establecer expresamente el medio ambiente como un bien jurídico que se protege en interés de una colectividad de carácter difusa, lo que sentó precedente en ese sentido. Nos estamos refiriendo al fallo dictado por la Excelentísima Corte Suprema en el marco del denominado "caso Trillium" ${ }^{\circ 0}$, que en su considerando $13 .{ }^{\circ}$ dispone que

\footnotetext{
${ }^{57}$ Cfr. DE LA BARRA GILI, F., "Responsabilidad...” cit., p. 398.

58 Para un estudio más acabado respecto a este punto, véase BORDALÍ SALAMANCA, A., “Titularidad..." cit. y DE LA BARRA GILI, F., "Responsabilidad...” cit.

59 Véase Sentencia de 24 de junio de 1999. Corte de Apelaciones de Concepción. Municipalidad de Antuco con Dirección de Obras Hidráulicas. Rol 351-98. Sentencia de 30 de agosto de 2000. Corte de Apelaciones de Concepción. Municipalidad de Santa Juana con Comisión Regional de Medio Ambiente VIII Región. Rol 252-99.

${ }^{60}$ Véase Sentencia de 19 de marzo de 1997. Corte Suprema. Girardi y otros con Comisión Regional de Medio Ambiente XII Región. Rol 2732-96.
} 
“[...] el derecho a vivir en un medio ambiente libre de contaminación es un derecho humano con rango constitucional, el que presenta un doble carácter: derecho subjetivo público y derecho colectivo público. El primer aspecto se caracteriza porque su ejercicio corresponde, como lo señala el artículo 19 de la Constitución Política a todas las personas, debiendo ser protegido y amparado por la autoridad a través de los recursos ordinarios y el recurso de protección. Y, en lo que dice relación con el segundo carácter del derecho en análisis, es decir, el derecho colectivo público, él está destinado a proteger y amparar derechos sociales de carácter colectivo, cuyo resguardo interesa a la comunidad toda, tanto en el plano local como en el nivel nacional, a todo el país, ello porque se comprometen las bases de la existencia como sociedad y nación, porque al dañarse o limitarse el medio ambiente y los recursos naturales, se limitan las posibilidades de vida y desarrollo no sólo de las actuales generaciones sino también de las futuras. En este sentido, su resguardo interesa a la colectividad por afectar a una pluralidad de sujetos que se encuentran en una misma situación de hecho, y cuya lesión, pese a ser portadora de un gran daño social, no les causa un daño significativo o apreciable claramente en su esfera individual".

Termina la Corte Suprema por concluir que

“[...] son titulares de este recurso, necesariamente, todas las personas naturales o jurídicas que habitan el Estado y que sufran una vulneración del derecho al medio ambiente libre de contaminación que asegura el articulo 19 No. 8 del texto fundamental".

Finalmente, resulta posible establecer que la legitimación activa para el ejercicio de las acciones tendientes a la protección del medio ambiente es, en general, de carácter restringido, vislumbrándose un atisbo de amplitud en el ámbito de la acción de protección, pero únicamente de manera aislada, lo cual permite determinar la debilidad de este elemento para la adecuada configuración del derecho de acceso a la justicia ambiental.

\subsection{Condiciones de igualdad en el acceso a la justicia ambiental en Chile}

Anteriormente se constató que, para hacer efectivamente viable el adecuado derecho de acceso a la justicia ambiental, era menester contar con un sistema que permitiera la 
interposición de acciones ante los tribunales correspondientes que no fuera prohibitivamente oneroso ${ }^{61}$.

Los conflictos relativos al medio ambiente suelen verificarse entre partes que se encuentran en desigualdad de condiciones. Por una parte, se encontrará el sujeto contaminador, constituido generalmente por una empresa, que cuenta con los medios necesarios para hacer frente a demandas que se interpongan en su contra, $y$, por otra, la colectividad afectada por dicha contaminación, que generalmente será un conglomerado de vecinos y ciudadanos de a pie que desconocen la norma que los protege y que no tienen recursos suficientes para costearse un abogado que los represente ante los tribunales de justicia, como tampoco para solventar los gastos derivados de la conformación de la prueba, cuyo peso, además, recae sobre ellos.

Si bien es cierto que la ley dispone de ciertas franquicias para facilitar el acceso a la justicia de personas de escasos recursos, como el privilegio de pobreza ${ }^{62}$ o la defensa de sus intereses a través de la Corporación de Asistencia Judicial ${ }^{63}$, en la práctica no constituyen una herramienta idónea destinada a igualar las posiciones de las partes ante un conflicto de naturaleza ambiental.

Es en este ámbito donde cobran importancia las ONG de carácter ambiental, que sin tener afán de lucro y gestionando recursos que generan para tales fines pueden vehicular las demandas colectivas. No obstante, para que ello sea efectivamente posible, previamente habrá de ampliarse la legitimación activa permitiéndoles expresamente el ejercicio de las acciones destinadas a la defensa y protección del medio ambiente y estableciendo un marco de actuación económica y social que les permita cumplir tal objetivo. Mientras ello no suceda, nos enfrentamos a otro aspecto que constituye una barrera a la implementación del derecho de acceso a la justicia ambiental ${ }^{64}$.

\section{La creación de los tribunales ambientales: un nuevo panorama para la implementación del derecho de acceso a la justicia ambiental en Chile}

\footnotetext{
${ }^{61}$ Véase el apartado I.2.6 supra.

${ }^{62}$ Véanse los artículos 129 y ss. del Código de Procedimiento Civil.

${ }^{63}$ Véase el artículo 600 del Código Orgánico de Tribunales.

${ }^{64}$ Ante la posibilidad de una acción popular, véase el apartado II.2.4. infra.
} 
Durante los últimos años, el derecho ambiental chileno ha experimentado un desarrollo a pasos agigantados, especialmente luego del ingreso de Chile en la Organización para la Cooperación y el Desarrollo Económicos (OCDE) y de los desafíos que de ello se derivaron.

Es en ese contexto donde se erige una nueva institucionalidad ambiental en el país, concretada en primer término por la Ley 20.147/2010, de 26 de enero, que crea el Ministerio, el Servicio de Evaluación Ambiental y la Superintendencia del Medio Ambiente, y en segundo término por la Ley 20.600/2012, de 28 de junio, que crea los tribunales ambientales.

A pesar de que son muchas las aristas posibles de analizar respecto a la creación de este nuevo ente jurisdiccional, a lo que se nos convoca en esta nota es a reflexionar acerca de las implicaciones que generará en cuanto al derecho de acceso a la justicia ambiental, verificando si contempla, y en qué medida, los elementos que hemos tratado en la primera parte de este trabajo.

\subsection{Desarrollo y aplicación de la normativa ambiental mediante la Ley 20.600/2012}

Es indiscutible el esfuerzo que ha realizado el legislador a lo largo de estos últimos años destinado al desarrollo de la normativa ambiental chilena, lo que es especialmente constatable por la implementación de una nueva institucionalidad ambiental a través de la dictación de las normas a que hemos estado haciendo mención.

El legislador ambiental, conociendo las deficiencias existentes en el sistema respecto a la aplicación efectiva de la normativa ambiental, ha pretendido corregirlas. Por ello, ha considerado el cumplimiento de la regulación ambiental "como un importante fundamento del Estado de Derecho, la buena gobernanza y el Desarrollo Sostenible"65, que propenda a "la certeza jurídica para la inversión, la protección del medio ambiente y el acceso a la justicia ambiental",66.

Solamente se podrá constatar, con mediana certeza, si efectivamente esta nueva institucionalidad viene a fortalecer la correcta aplicación de la normativa ambiental,

\footnotetext{
${ }^{65}$ Véase el Mensaje No $1419-357$ de S. E. la Presidenta de la República, con el que inicia un proyecto de Ley que crea el Tribunal Ambiental, de 28 de octubre de 2009.

${ }^{66}$ Ibíd.
} 
cuando se encuentren en pleno funcionamiento, a lo largo de un tiempo prudencial, tanto la Superintendencia del Medio Ambiente - organismo administrativo fiscalizador con competencias regulatorias y de sanción- como los tribunales ambientales. Se espera que estos, a través de la actividad jurisdiccional de los jueces que los componen, en el cumplimiento de su rol en el sistema de contrapesos respecto de las intervenciones ambientales de las autoridades públicas y en la protección del derecho de las personas a vivir en un medio ambiente libre de contaminación, logren proporcionar un adecuado derecho de acceso a la justicia ambiental.

Sin perjuicio de lo anterior, hemos considerado de interés realizar un análisis acerca de la normativa actualmente vigente, aun cuando las autoridades no hayan entrado propiamente en ejercicio, aunque sea en el intento de observar prima facie el ideario perseguido por el legislador.

\subsection{Autoridades idóneas para conocer los asuntos ambientales en la Ley 20.600/2012}

Conforme al análisis realizado precedentemente, se ha podido constatar que no existían en Chile órganos jurisdiccionales especializados que conocieran de los asuntos suscitados en la esfera medioambiental. Siendo, por una parte, la Corte de Apelaciones respectiva el tribunal competente para conocer de las acciones de protección ambiental $\mathrm{y}$, por otra, los tribunales ordinarios civiles los competentes para conocer de las acciones indemnizatoria ordinaria y ambiental.

Esta carencia de órganos jurisdiccionales especializados en materia ambiental está siendo subsanada a través de la gradual entrada en funcionamiento de los tribunales ambientales, cuya función, en general, consiste en "resolver las controversias medioambientales de su competencia y ocuparse de los demás asuntos que la ley somete a su conocimiento",67.

Cada tribunal ambiental debe estar integrado por tres ministros ${ }^{68}$, teniendo dos de ellos la calidad de letrados y un tercero la calidad de experto en el ámbito de las ciencias con

\footnotetext{
${ }^{67}$ Véase el artículo $1 .^{\circ}$ de la Ley 20.600/2012, de 28 de junio, que crea los tribunales ambientales.

${ }^{68}$ El proyecto original, iniciado por el Mensaje $N^{\circ} 1419-357$, de 28 de octubre de 2009, establecía que el Tribunal Ambiental estaría integrado por cinco ministros: tres abogados y dos profesionales de las ciencias y la economía.
} 
especialización en materias medioambientales ${ }^{69}$. La razón esgrimida para fundamentar esta composición mixta se encuentra en el Mensaje que dio inicio a la tramitación del proyecto de Ley cuando dispone que

“[...] la razón de esta integración está en que las cuestiones ambientales se mueven en un espacio de conocimiento altamente especializado pero también incierto, por lo cual no sólo es razonable que puedan resolver las discrepancias los jueces letrados, sino que también quienes no invisten tal calidad, pero que disponen de otra especialización que contribuye a una razonable y acabada decisión de los asuntos ambientales" $" 70$.

Si bien es cierto que los asuntos ambientales requieren un equipo multidisciplinario para su acertada resolución, la doctrina no ha sido completamente pacífica respecto a la fórmula ideada por el legislador para crear el marco apropiado. Ciertos autores han sostenido que los tribunales ambientales deberían estar integrados únicamente por jueces letrados con formación, capacidad e idoneidad para "decir Derecho", salvándose la necesidad de contar con conocimiento científico concreto mediante la asesoría y aportación de informes de un comité de expertos, que habría de nombrarse para estos efectos. $^{71}$

La Ley que crea los tribunales ambientales también hace referencia a la cantidad de tribunales ambientales que se han de instaurar en el país y el ámbito de competencia territorial de cada uno de ellos ${ }^{72}$, disponiendo en su artículo 5. ${ }^{\circ}$ que serán tres: un primer

\footnotetext{
${ }^{69}$ Véase el artículo 2.1 de la Ley 20.600/2012, de 28 de junio, que crea los tribunales ambientales: "Cada Tribunal Ambiental estará integrado por tres ministros. Dos de ellos deberán tener título de abogado, haber ejercido la profesión a lo menos diez años y haberse destacado en la actividad profesional o académica especializada en materias de Derecho Administrativo o Ambiental. El tercero será un licenciado en Ciencias con especialización en materias medioambientales y, a lo menos, diez años de ejercicio profesional".

${ }^{70}$ Véase el Mensaje $\mathrm{N}^{\circ} 1419-357$ cit.

${ }^{71}$ Cfr.: PROGRAMA DE DERECHO Y POLÍTICA AMBIENTAL, Facultad de Derecho, Universidad Diego Portales (2012, 30 de abril). Comentarios acerca del proyecto de Ley que crea los tribunales ambientales (Boletín $\mathrm{N}^{\mathrm{o}}$ 6747-12). Recuperado el 30 de abril de 2012, de: $<$ www.derechoambiental.udp.cl/?p=1059>.

72 Véase el artículo 5 de la Ley 20.600/2012, de 28 de junio, que crea los tribunales ambientales: "Número de Tribunales y Jurisdicción. Créase un Tribunal Ambiental con asiento en cada una de las siguientes comunas del territorio de la República, con jurisdicción territorial que en cada caso se indica: a) Primer Tribunal Ambiental, con asiento en la comuna de Antofagasta, y con competencia territorial en las Regiones de Arica y Parinacota, de Tarapacá, de Antofagasta, de Atacama y de Coquimbo. b) Segundo Tribunal Ambiental, con asiento en la comuna de Santiago, del Libertador General Bernardo O'Higgins y del Maule. c) Tercer Tribunal Ambiental, con asiento en la comuna de Valdivia, y con competencia territorial en las Regiones del Biobío, de La Araucanía, de Los Ríos, de Los Lagos, de Aysén del General Carlos Ibáñez del Campo, y de Magallanes y de la Antártica Chilena”.
} 
Tribunal Ambiental con asiento en la comuna de Antofagasta, un segundo Tribunal Ambiental con asiento en la comuna de Santiago y un tercer Tribunal Ambiental con asiento en la comuna de Valdivia.

En una primera etapa de tramitación del proyecto de Ley que crea los tribunales ambientales $^{73}$, se estableció que se implementaría un único tribunal ambiental con sede en la ciudad de Santiago, permitiendo, sin embargo, presentaciones a nivel regional ante las intendencias regionales o gobernaciones provinciales. Las razones esgrimidas en el Mensaje del proyecto de Ley para establecer un tribunal ambiental de carácter único fueron, por una parte, su suficiencia para una primera etapa dada la demanda de causas actual y esperable, y, por otra, la predecibilidad en relación con sus precedentes, tendiente a la contribución de la seguridad jurídica ${ }^{74}$.

Esta disposición fue controvertida especialmente desde las ONG de carácter ambiental y determinados sectores del mundo académico, quienes argumentaron que la creación de un único tribunal ambiental para todo el país significaba una vulneración al derecho de acceso a la justicia ambiental al no garantizar la expedita y debida administración de justicia que se requiere en estas materias, especialmente considerando que la mayoría de los conflictos ambientales ocurren fuera de la Región Metropolitana, con lo cual se perjudicaría la realización del derecho a la participación ciudadana en materia ambiental respecto de las regiones y de las comunidades con menos recursos ${ }^{75}$.

Este debate propendió a que el legislador terminara por considerar que, en definitiva, se justificaba la existencia de tres tribunales distribuidos de forma equidistante a lo largo del país, asumiendo "un cierto compromiso de que dependiendo de cómo éstos funcionen se podría ir sumando uno por región" tribunales ambientales que ha establecido la Ley solamente podrá ser verificada una vez transcurrido un plazo prudencial contado desde la instauración y el funcionamiento de los tribunales ambientales.

\footnotetext{
${ }^{73}$ Véase el Mensaje No $1419-357$, cit.

${ }^{74}$ Véase el Mensaje No $1419-357$, cit.

75 Cfr. DOUGNAC RODRÍGUEZ, F., "Tribunales ambientales: sueño u operatividad”, El Mostrador (2009, 24 de noviembre). Recuperado el 15 de abril 2012, de $<$ http://www.elmostrador.cl/opinion/2009/11/24/tribunales-ambientales-sueno-u-operatividad/>.

${ }^{76}$ Véase la opinión del jurista CORDERO VEGA, L., "Tribunales Ambientales: la pieza faltante de la institucionalidad ecológica", El Mercurio Legal (2011, 27 de noviembre). Recuperado el 18 de abril de 2012, de: <http://www.elmercurio.com/Legal/Noticias/Noticias-y-reportajes/2011/11/27/TribunalesAmbientales-la-pieza-faltante-de-la-institucionalidad-ecologica.aspx $>$.
} 
2.3. Mecanismos de resolución de conflictos ambientales establecidos en la Ley $20.600 / 2012$

A rasgos generales, hemos podido constatar que en el derecho chileno los mecanismos de resolución de problemas ambientales se han centrado principalmente en sede jurisdiccional para el conocimiento de las acciones de protección y aquellas que persiguen la responsabilidad extracontractual por daño ambiental.

Actualmente, integra esta sede jurisdiccional un nuevo organismo de carácter especializado para el conocimiento de cuestiones ambientales: los tribunales ambientales.

Resulta interesante destacar que en el Mensaje por el cual se dio inicio al proyecto de Ley se consideró el tribunal ambiental como "un organismo jurisdiccional de carácter exclusivo para cuestiones ambientales",77, pretensión que, acto seguido, flexibiliza al establecer que sus competencias habrían de estar asociadas a la integralidad de la regulación ambiental, refiriéndose específicamente a "todas las atribuciones contenciosas administrativas de la ley $\mathrm{N}^{\mathrm{o}} 19.300^{,, 78}$.

El título II de la Ley 20.600/2012 contempla las normas relativas a la competencia de los tribunales ambientales. El artículo 17 dispone expresamente la enumeración de las competencias, la mayoría de las cuales guardan relación con el conocimiento de reclamaciones que se interpongan en contra de actos administrativos de carácter ambiental $^{79}$, perfilándose, por lo tanto, como un tribunal de lo contenciosoadministrativo ambiental. Hacen excepción a tal situación la atribución establecida en el número 4 del artículo señalado, relativa al conocimiento de ciertas solicitudes referentes a medidas provisionales, suspensiones y aplicación de ciertas sanciones, y la atribución establecida en el número 2 del mismo artículo, por cuanto se le otorga también competencia para conocer de las demandas destinadas a obtener la reparación del medio ambiente dañado. En este último caso, hay una transferencia expresa a estos tribunales

\footnotetext{
${ }^{77}$ Véase el Mensaje № 1419-357, cit.

${ }^{78}$ Ibíd.

${ }^{79}$ Se trata de reclamaciones principalmente relativas a los actos regulatorios, calificaciones ambientales expedidas en segunda instancia administrativa, invalidaciones y revisiones de resoluciones de calificación ambiental, y sanciones aplicadas por la Superintendencia del Medio Ambiente. Cfr. GUZMÁN ROSEN, R., Derecho Ambiental Chileno. Principios, instituciones, instrumentos de gestión, Planeta Sostenible, Santiago de Chile, 2012, p. 240.
} 
ambientales de la competencia que antes se encontraba arrogada a los juzgados de letras en lo civil ${ }^{80}$.

En último término, se puede observar que en ningún caso la normativa actual otorga a esta nueva institución la exclusividad en el conocimiento de cuestiones ambientales, toda vez que deja al margen de su conocimiento competencias relativas al ámbito ambiental sectorial, como es el caso del recurso hídrico, la biodiversidad, el ámbito forestal o la pesca, entre otros ${ }^{81}$.

La Ley 20.600/2012, además de determinar la competencia específica de los tribunales ambientales, también establece, en su título III, los procedimientos a través de los cuales los jueces habrán de ejercer estas atribuciones. Se dispone en el párrafo $2 .^{\circ}$ el procedimiento de las reclamaciones; en el párrafo $3 .^{\circ}$, el procedimiento de las solicitudes; y en el párrafo $4 .^{\circ}$, el procedimiento por daño ambiental. Asimismo, en el párrafo $1 .^{\circ}$ del título referido, la Ley contempla las disposiciones comunes a estos tres procedimientos señalados $\mathrm{y}$ en su párrafo final hace referencia a la acción de indemnización de perjuicios por la producción de daño ambiental, el órgano jurisdiccional competente para su conocimiento y su procedimiento específico.

Determinar si estos procedimientos que se desarrollarán ante los tribunales ambientales proporcionarán en la práctica una solución completa y expedita que asegure una rápida y adecuada reparación será labor de estudios que se generarán una vez que los tribunales empiecen a funcionar como tales. Si bien es cierto que desde el 28 de diciembre de 2012 se encuentra en funcionamiento el segundo Tribunal Ambiental (el primero en ser instaurado), al 2 de abril del año en curso solamente ha sido sometida a su conocimiento una primera causa ${ }^{82}$, razón por la cual aún no es posible realizar conjeturas al respecto.

Ahora bien, si nos atenemos únicamente a lo que dispone la Ley, teóricamente resulta posible realizar cierto pronóstico acerca de la idoneidad del mecanismo de resolución establecido en cada uno de los procedimientos contemplados, tomando como

\footnotetext{
${ }^{80}$ Véase la nota al pie 39 supra.

${ }^{81}$ Tal como sucede respecto al conocimiento de las infracciones a la Ley 20.283/2008, de 30 de julio, sobre recuperación del bosque nativo y fomento forestal, que son y seguirán siendo competencia del juez de Policía Local, conforme lo dispone su artículo 45.

${ }^{82}$ Se trata de una reclamación interpuesta por Barrick Gold Corporation contra la Superintendencia del Medio Ambiente. Véase LEXWEB.CL (2013, 2 de abril), "Tribunal Ambiental acoge su primer caso". Recuperado el 10 de abril de 2013, de http://www.lexweb.cl/tribunal-ambiental-acoge-primer-casobarrick.
} 
indicadores aquellos principios formativos del procedimiento que sugieren un avance en términos de acceso a la justicia ambiental.

Se establece, mediante el artículo 21 de la Ley 20.600/2012 $2^{83}$, que regirá en los procedimientos que ella contempla el principio de oficialidad. Si bien es cierto que tanto el procedimiento relativo a las reclamaciones como el relativo al daño ambiental se inician a instancia de parte, conforme lo disponen los artículos 27 y 33 de la Ley 20.600/2012, ello no obsta a que sea el propio Tribunal el encargado de realizar todas las actuaciones pertinentes con el objeto de hacer avanzar el procedimiento, independientemente de previa solicitud de parte.

El mismo artículo 21 de la norma en comento contempla también el principio de publicidad. Un procedimiento público permite el amplio conocimiento de la causa por parte de la sociedad civil, lo que favorece, eventualmente, su participación, sea como tercero, sea mediante la aportación de informes en calidad de amicus curiae, proporcionando, así, una resolución más completa.

Durante la tramitación del proyecto de Ley por el cual se crean los tribunales ambientales, desde la sociedad civil, a través de determinadas $\mathrm{ONG}$, se abogaba por un sistema que contemplase un procedimiento oral ${ }^{84}$, dado que a través de la oralidad tienen total cabida los principios de inmediación y se propende a la concentración y a la economía procesal. Además, no se trataría de la primera experiencia en Chile, en términos de oralidad en un procedimiento, debido a que ya se habían llevado a cabo la reforma procesal penal durante el año 2000, la reforma de los tribunales de familia el año 2005 y la reforma de los tribunales laborales el año 2008, todos los cuales se basan en dicho principio.

Esta recomendación, sin embargo, terminó no adoptándose, rigiendo mayormente la escrituración en los procedimientos de reclamo, de solicitudes y de daño ambiental, con

\footnotetext{
${ }^{83}$ Artículo 21 de la Ley 20.600/2012, de 28 de junio, que crea los tribunales ambientales: "Publicidad del procedimiento y representación de las partes. El procedimiento será público e impulsado de oficio por el Tribunal hasta su resolución definitiva. Las partes deberán actuar representadas en la forma prevista en la LEY No 18.120 , sobre comparecencia en juicio".

${ }^{84}$ OJO CON EL PARLAMENTO Y CHILE SUSTENTABLE (2010, 20 de agosto), "Proyecto de Ley que crea los tribunales ambientales". Minuta de tramitación en el Senado del Congreso Nacional. $\begin{array}{llllll}\text { Recuperado el } & 11 & \text { de } & \text { abril }\end{array}$ http://diariodelderechoambiental.bligoo.com.ar/media/users/8/417260/files/31290/Minuta-TramitacionTribunales-Ambientales-Senado-Agosto-2010.pdf.
} 
algunos atisbos de oralidad $^{85}$ como, por ejemplo, la audiencia de conciliación, formulación de alegaciones y prueba en el procedimiento por daño ambiental ${ }^{86}$.

Al prevalecer la escrituración, necesariamente se han de establecer una serie de plazos entre una y otra presentación y sus correspondientes resoluciones, lo que redunda no solo en la extensión en el tiempo del procedimiento, sino también en el incremento de los costes del juicio.

Respecto al procedimiento por daño ambiental, el Tribunal ambiental conocerá de la acción ambiental propiamente tal que persigue la reparación del medio ambiente dañado. Se trata de la misma acción que antes era conocida por los tribunales letrados civiles competentes a través del procedimiento sumario ${ }^{87}$.

Si bien la Ley 20.600/2012 establece un procedimiento especial para el conocimiento de esta acción, aparentemente, en atención a las etapas que contempla, no implicará una mayor celeridad respecto del procedimiento sumario que regía anteriormente, lo que significa que no hay verdaderamente una evolución en sentido de favorecer el acceso a la justicia ambiental a este respecto.

Asimismo, la Ley 20.600/2012 se refiere a la acción de indemnización de perjuicios por la producción de un daño ambiental que haya sido establecida en una sentencia por el tribunal ambiental, y aunque establece un procedimiento especial para su conocimiento, dispone que esta será conocida por el juzgado de letras en lo civil con competencia en el lugar donde se produjo el daño ${ }^{88}$.

Esta situación generó bastante controversia a nivel de sociedad civil, la cual consideró que era un sinsentido que la acción indemnizatoria no fuera conocida también por el

\footnotetext{
85 Siguiendo a Montero Aroca y Gómez Redondo: "Desde el inicio hay que dejar bien sentado, por evidente, la imposibilidad práctica de configurar un procedimiento de manera totalmente oral o escrita. De ahí que no se trate de exclusividades sino de prevalecimientos. Resulta así que el problema de los principios de oralidad o de escritura es un problema de límites. Si en un procedimiento escrito la palabra ha de ser la forma de realización de algunos actos procesales, y si de un procedimiento oral la escritura no puede estar totalmente ausente, todo se reduce a determinar cuándo, por prevalecer una forma u otra, podemos correctamente decir que estamos ante un procedimiento oral o escrito"; en MONTERO AROCA, J. et ál., Derecho Jurisdiccional, parte general, tomo I, Tirant Lo Blanch, 16. ed., Valencia, 2008, p. 393.

${ }^{86}$ Véanse los artículos 36, 37 y 38 de la Ley 20.600/2012, de 28 de junio, que crea los tribunales ambientales.

${ }^{87}$ Véase el apartado II.1.3 supra.

${ }^{88}$ Véase el artículo 46 de la Ley 20.600/2012, de 28 de junio, que crea los tribunales ambientales.
} 
tribunal ambiental ${ }^{89}$, advirtiendo, además, que no se modificaba el sistema de responsabilidad subjetivo por culpa o negligencia por el cual le corresponde la carga de la prueba a quien alega dicha responsabilidad.

Aun cuando no se hayan presentado modificaciones en las bases mismas del sistema de prueba de la responsabilidad, hubo una modificación respecto a los informes periciales que marca una evolución en cuanto al derecho de acceso a la justicia ambiental. La nueva normativa permite la utilización real de dicho medio probatorio por aquella parte que no cuente con medios suficientes para disponer de él por si misma, dado que el tribunal la puede eximir del elevado costo que supone ${ }^{90}$.

Finalmente, solo cabe agregar que la posibilidad de recurrir ante la Corte de Apelaciones para interponer la acción de protección constitucional sigue aún vigente.

\subsection{Legitimación activa ante los tribunales ambientales chilenos}

El derecho de acción se encuentra reconocido en el artículo 18 de la Ley 20.600/2012, que podrá ser ejercitado a través de reclamación, de solicitud o de demanda únicamente por aquellas personas autorizadas para intervenir en el procedimiento en calidad de parte, conforme a la enumeración que dispone la norma referida. Esta enumeración se correlaciona a la enumeración de las competencias señaladas en el artículo $17^{91}$, acotando así los legitimados o grupos de legitimados que pueden acudir al tribunal por cada una de las competencias establecidas ${ }^{92}$.

\footnotetext{
${ }^{89}$ OJO CON EL PARLAMENTO Y CHILE SUSTENTABLE (2010, 20 agosto), "Proyecto de Ley que crea los tribunales ambientales". Minuta de tramitación en el Senado del Congreso Nacional. Recuperado el 11 de abril de $2013, \quad$ de http://diariodelderechoambiental.bligoo.com.ar/media/users/8/417260/files/31290/Minuta-TramitacionTribunales-Ambientales-Senado-Agosto-2010.pdf.

${ }^{90}$ Véase el artículo 42.3 de la Ley 20.600/2012, de 28 de junio, que crea los tribunales ambientales.

${ }^{91}$ Así, por ejemplo, conforme dispone el número 1 del artículo 18, está legitimada para interponer la reclamación del número 1 del artículo 17 (reclamaciones en contra de los decretos supremos que establezcan las normas primarias o secundarias de calidad ambiental y las normas de emisión...) cualquier persona que considere que los decretos que tal numeral menciona no se ajustan a la Ley $\mathrm{N}^{\circ}$ 19.300 y le causen perjuicio. Conforme al número 2 del artículo 18, están legitimadas para interponer la demanda del número 2 del artículo 17 (para obtener la reparación del medio ambiente dañado) las personas naturales o jurídicas que hayan sufrido el daño o perjuicio, las municipalidades, por los hechos acaecidos en sus respectivas comunas, y el Estado, por intermedio del Consejo de Defensa del Estado (...).

92 Cfr. OLIVARES CORTÉS, C. (2010, 15 de octubre), "Legitimación activa en los Tribunales Ambientales". Blog del Centro de Derecho Ambiental. Recuperado el 17 de septiembre 2012, de http://www.derecho-ambiental.cl/2010/07/legitimacion-activa-en-los-tribunales.html.
} 
Resulta interesante analizar la evolución que se produjo respecto al tema de la legitimación activa, debido a que la normativa actualmente vigente, en este sentido, dista mucho de lo que en sus inicios establecía el proyecto de Ley que crea los tribunales ambientales, el cual disponía, en su primitivo artículo 18: "Estarán legitimados para intervenir ante el tribunal las personas naturales o jurídicas que se encuentren en alguna de las hipótesis señaladas en el artículo 21 de la Ley N ${ }^{\circ} 19.880 "$.

Remitiéndonos a la norma mencionada ${ }^{93}$, en el proyecto de Ley estaban legitimados para ejercer las reclamaciones, demandas o solicitudes correspondientes ante los tribunales ambientales, sin distinción respecto a competencias específicas, los siguientes "interesados": "1. Quienes lo promuevan como titulares de derechos o intereses individuales o colectivos. 2. Los que, sin haber iniciado el procedimiento, tengan derechos que puedan resultar afectados por la decisión que en el mismo se adopte. 3 . Aquéllos cuyos intereses, individuales o colectivos, puedan resultar afectados por la resolución y se apersonen en el procedimiento en tanto no haya recaído resolución definitiva". 94

Conforme al actual texto del artículo 18 de la Ley 20.600/2012, son legitimados activos para comparecer en calidad de partes ante el tribunal ambiental competente: 1) cualquier persona que considere que los decretos supremos (que establecen normas de calidad ambiental, normas de emisión, zonas latentes o saturadas y planes de prevención o descontaminación) no se ajustan a la ley y le causan perjuicio; 2) las personas naturales o jurídicas que hayan sufrido el daño, las municipalidades y el Estado, por intermedio del Consejo de Defensa del Estado, en casos de daño ambiental; 3) las personas naturales o jurídicas directamente afectadas por resoluciones de la Superintendencia del Medio Ambiente; 4) la Superintendencia del Medio Ambiente para solicitar la autorización de medidas provisionales, suspensiones y sanciones; 5) las personas naturales o jurídicas que presenten reclamaciones en contra de resoluciones del Comité de Ministros o del director ejecutivo cuando consideren que sus observaciones no hubieren sido apreciadas en el procedimiento de evaluación ambiental; 6) cualquier persona que considere que los actos administrativos que dicten los ministerios o

\footnotetext{
${ }^{93}$ MINISTERIO SECRETARÍA GENERAL DE LA PRESIDENCIA. Ley 19.880/2003, de 29 de mayo, que establece bases de los procedimientos administrativos que rigen los actos de los órganos de la administración del Estado.

94 Artículo 21 de la Ley 19.880/2003, de 29 de mayo, que establece bases de los procedimientos administrativos que rigen los actos de los órganos de la administración del Estado.
} 
servicios públicos para la ejecución o implementación de las normas de calidad, emisión y planes de prevención o descontaminación, infrinjan la ley, las normas y/o los objetivos de los instrumentos señalados; 7) las personas que hayan solicitado la invalidación administrativa de un acto administrativo de carácter ambiental o las personas afectadas por las resoluciones que resuelvan dichos procedimientos de invalidación.

En consecuencia, es posible observar que la legitimación activa permitía, en el proyecto originario, un acceso más generalizado; en cambio, en la normativa actual la legitimación activa se restringe al establecer filtros de acceso para cada una de las competencias de los tribunales ambientales. El objetivo perseguido por el legislador para configurar estos filtros, según el académico Julio Lavín, sería la de “prevenir los riesgos de una excesiva judicialización"95.

Desde las organizaciones no gubernamentales ha habido cierta crítica a este respecto ${ }^{96}$, al considerar que en ninguna de las etapas de la tramitación de la norma y, finalmente, tampoco en su redacción final se ha contemplado de manera expresa la participación de las ONG de carácter ambiental como entes legitimados para comparecer ante los tribunales ambientales.

Hubiera sido deseable, conforme a lo que hemos indicado anteriormente ${ }^{97}$, que, al menos en lo que a acción ambiental se refiere, la Ley 20.600/2012 contemplara expresamente la participación de las ONG de carácter ambiental como legitimados activos en defensa del interés difuso. Desafortunadamente, primó la argumentación de aquel sector que se declara detractor de la acción popular, según la cual a través de este sistema se produciría "un interminable peregrinar de demandas particulares con un serio peligro para la seguridad jurídica" ${ }^{98}$.

\footnotetext{
${ }^{95}$ PROGRAMA DE DERECHO Y POLÍTICA AMBIENTAL, Facultad de Derecho, Universidad Diego Portales (2010, 27 de septiembre). Comentarios acerca del proyecto de Ley que crea los tribunales ambientales (Boletín No 6747-12). Recuperado el 30 de abril de 2012, de $<$ www.derechoambiental.udp.cl/?p=1059>.

${ }^{96}$ OJO CON EL PARLAMENTO Y CHILE SUSTENTABLE (2010, 20 de agosto), "Proyecto de Ley que crea los tribunales ambientales". Minuta de tramitación en el Senado del Congreso Nacional, cit.

${ }^{97}$ Véase el apartado II.1.4. supra.

98 BORDALÍ SALAMANCA, A., "Titularidad..." cit. p. 57, quien se ha mostrado a favor de la implementación de la acción popular.
} 
Eventualmente, pudiera haberse formulado la inclusión de una especie de "acción semipopular" restringida únicamente a las ONG de carácter ambiental, tal como la que se establece en el ordenamiento jurídico español ${ }^{99}$, el cual, para evitar cuestiones de excesiva judicialización, ha establecido una serie de requisitos destinados a filtrar la participación de estas entidades. Tales requisitos son: a) tener entre los fines acreditados en sus estatutos la protección del medio ambiente en general o en alguno de sus elementos en particular; b) estar constituida legalmente al menos dos años antes del ejercicio de la acción y venir ejerciendo de modo activo las actividades necesarias para el cumplimiento de los fines que establece su estatuto; y c) desarrollar su actividad en el ámbito territorial que resulte afectado por la acción u omisión administrativa que vaya a ser objeto de impugnación ${ }^{100}$.

No obstante, aun cuando estas organizaciones no puedan involucrarse en el proceso en calidad de parte, salvo que se encuentren en uno de los casos que contempla la enumeración del artículo 18 de la Ley 20.600/2012, podrán hacerlo siempre en calidad de amicus curiae.

El artículo 19 de la Ley 20.600/2012 dispone que son amicus curiae "cualquier persona, natural o jurídica, que no sea parte en el proceso, que posea reconocida idoneidad técnica y profesional en la materia objeto del asunto sometido al conocimiento del Tribunal ambiental y que invoque la protección de un interés público”. Tales personas podrán presentar sus comentarios, observaciones o sugerencias durante la tramitación de una causa, la cual, sin tener efecto vinculante, deberá ser considerada en la sentencia definitiva.

Sobre la base de lo anterior, si bien la Ley 20.600/2012 terminó por restringir la legitimación activa respecto de lo que se establecía en el proyecto inicial, el esfuerzo por parte de los legisladores de incorporar la figura del amicus curiae favorece la participación de ONG ambientales en los juicios que versen sobre asuntos ambientales. Además, ello es digno de destacar porque es la primera vez que se incorpora esta figura

\footnotetext{
${ }^{99}$ Para ahondar en este tema, véase RUIZ DE APODACA ESPINOSA, A., "La acción pública ambiental: una necesidad satisfecha parcialmente por la Ley 27/2006, de 18 de julio", Revista Aranzadi de Derecho Ambiental, núm. 11, 2007.

${ }^{100}$ Véase el artículo 23 de la Ley 27/2006, de 18 de julio, por la que se regulan los derechos de acceso a la información, de participación pública y de acceso a la justicia en materia de medio ambiente.
} 
en la legislación chilena mediante la aceptación de observaciones que se realizaron desde la sociedad civil durante la tramitación del proyecto.

En definitiva, a través del establecimiento de la figura del amicus curiae no solo se fortalece la legitimación activa, sino que también se tiende al desarrollo normativo ambiental de una forma democrática al haber sido propuesta mediante la participación ciudadana.

\subsection{Condiciones de igualdad en el acceso a la justicia ambiental en la Ley 20.600/2012}

Hemos podido apreciar que el derecho de acceso a la justicia está también condicionado a la capacidad económica de los sujetos involucrados para poder ejercer la acción. Conforme a esta afirmación, durante la tramitación del proyecto de Ley por el cual se crearon los tribunales ambientales, las organizaciones ciudadanas presentaron una propuesta que pretendía establecer un fondo público para financiar la participación de los sectores de menores ingresos en las causas.

Esta propuesta finalmente no fue acogida y tampoco se estableció ninguna otra, manteniéndose, en consecuencia, las fórmulas fijadas en la normativa general: el privilegio de pobreza y la defensa a través de la Corporación de Asistencia Judicial, que, conforme habíamos analizado previamente, no constituyen una herramienta idónea para intentar igualar las posiciones de las partes ante un conflicto de naturaleza ambiental.

La única novedad que dispone la Ley 20.600/2012 en este sentido es la que hace referencia a los honorarios y gastos derivados de la intervención de los peritos en los procedimientos por daño ambiental, en virtud de la cual el tribunal, de manera excepcional, podrá eximir a la parte total o parcialmente del pago del honorario del perito cuando considere que esta no cuenta con medios suficientes para solventarlo. Este coste será de cargo del Estado ${ }^{101}$.

A la postre, la evolución del derecho de acceso en este sentido es mínima, no pudiendo considerarse que haya resuelto el tema de equidad de las partes en los procedimientos ambientales.

\footnotetext{
${ }^{101}$ Véase el artículo 42.3 de la Ley 20.600/2012, de 28 de junio, que crea los tribunales ambientales.
} 


\section{REFLEXIONES FINALES}

Hasta el año recién pasado, el sistema judicial chileno carecía de una institución que se avocara única y exclusivamente al conocimiento de asuntos de índole medioambiental. Estos casos eran conocidos hasta entonces por los tribunales de letras en lo civil y por las cortes de apelaciones.

Mediante la Ley 20.600/2012, de 28 de junio, se crearon los tribunales ambientales en Chile. Sin embargo, a día de hoy aún no tenemos antecedentes para poder calificar su actuación y para determinar si en la práctica significará una evolución respecto del derecho de acceso a la justicia ambiental, toda vez que el primero de ellos entró recién en funcionamiento el día 28 de diciembre del año pasado y solamente al día 2 de abril de 2013 ingresó su primera causa.

A pesar de lo anterior, resulta posible aplicar los elementos que configuran el derecho de acceso a la justicia como herramienta de análisis teórico respecto de la propia Ley 20.600/2012, verificando algunas de sus limitaciones y virtudes respecto del sistema que regía con anterioridad a su entrada en vigor.

1. Respecto al elemento de desarrollo de la normativa ambiental, resulta indudable que la Ley 20.600/2012, de 28 de junio, que crea los tribunales ambientales, viene a incorporarse al conjunto de normativas ya existentes y significa una evolución en este aspecto, si bien su cumplimiento aún está por verificarse cuando el sistema comience a regir completamente.

2. Consideramos que la conformación de una autoridad especializada en temas ambientales constituye un avance en el tema del derecho de acceso a la justicia ambiental. No obstante, estamos de acuerdo con la postura que considera que los tribunales ambientales deberían estar compuestos únicamente por juristas con formación en derecho ambiental. Aun cuando no desconocemos la importancia de otras ciencias y disciplinas, que habrá de tomarse en consideración atendiendo a la característica multidisciplinaria de las cuestiones ambientales, ello podría haber sido salvado mediante la implementación de un panel permanente de expertos como ente colaborador de la judicatura ambiental.

3. Con relación a los procedimientos establecidos en la Ley 20.600/2012 como mecanismos de resolución de conflictos, consideramos que no vienen a revolucionar el sistema anterior debido a que, al menos en lo que en teoría dispone la norma, no 
significarán una mayor celeridad respecto a los procedimientos previamente existentes. Expresión propia de ello es el mantenimiento del sistema de responsabilidad extracontractual subjetiva por dolo, culpa o negligencia.

4. A propósito de la legitimación activa, hemos de estimar que hubo un avance que, si bien es más restringido que el que se proponía mediante el proyecto inicial de la Ley 20.600/2012, favorece la participación ciudadana mediante la incorporación de la figura del amicus curiae.

5. En lo que respecta al establecimiento de unas condiciones que permitan a las partes situarse en posiciones equitativas en atención a los costes que habrán de sufragar, la incidencia de la nueva institucionalidad es mínima. Se establece para el caso de las demandas por daño ambiental la posibilidad de eximir a la parte que carece de recursos económicos del costo que supone la generación de un informe pericial, lo que indudablemente resulta insuficiente para considerar que las partes se encuentran en igualdad de condiciones.

Finalmente, habrá que estar atento a las próximas actuaciones del segundo Tribunal Ambiental (el único que actualmente se encuentra en funcionamiento), y luego a la incorporación del primero y tercero el próximo 28 de diciembre del presente año, para verificar la forma en que se implementará en la práctica el derecho de acceso a la justicia ambiental en Chile, toda vez que el avance que se ha constatado al día de hoy, conforme a los parámetros generales que hemos analizado, resulta, a nuestro juicio, insuficiente.

\section{REFERENCIAS BIBLIOGRÁFICAS}

AA. VV., Acceso a la información, participación y justicia en temas ambientales en Chile: ¿Cuánto hemos avanzado?, Resumen ejecutivo, The Access Initiative, Santiago de Chile, 2005.

BARROS BOURIE, E., "Responsabilidad civil en materia de medio ambiente", Derecho del Medio Ambiente, Fundación Facultad de Derecho, Universidad de Chile, Editorial Jurídica Conosur Ltda., Santiago de Chile, 1998, pp. 47-65.

BENÍTEZ RAMÍREZ, E., "Principios procesales relativos a las partes", Revista Chilena de Derecho, núm. 34, tomo III, 2007, pp. 591-593. 
BERMÚDEZ SOTO, J., "El acceso a la información pública y la justicia ambiental", Revista de Derecho de la Pontificia Universidad Católica de Valparaíso, núm. 34, ${ }^{\text {er }}$ semestre de 2010, pp. 571-596.

BORDALÍ SALAMANCA, A., "Titularidad y legitimación activa sobre el ambiente en el derecho chileno", Revista de Derecho de la Universidad Austral de Chile, núm. 9, diciembre de 1998, pp. 43-64.

BRAÑES BALLESTEROS, R., "El acceso a la justicia ambiental en América Latina: Derecho Ambiental y Desarrollo Sostenible", en Simposio Judicial Derecho Ambiental y Desarrollo Sostenible. El acceso a la justicia ambiental en América Latina, del 26 al 28 de enero de 2000, Ciudad de México, Programa de Naciones Unidas para el Medio Ambiente y Procuraduría Federal de Protección al Ambiente, Gobierno de México, pp. 34-87.

DE LA BARRA GILI, F., "Responsabilidad extracontractual por daño ambiental: El problema de la legitimación activa", Revista Chilena de Derecho, núm. 29, tomo II, 2002, pp. 367-415.

DOMÍNGUEZ BALMACEDA, J. P., "Principios procesales relativos al procedimiento", Revista Chilena de Derecho, núm. 34, tomo III, 2007, pp. 595-598.

DOUGNAC RODRÍGUEZ, F., "La Garantía del Nº del artículo 19 de la Constitución como Derecho Humano", Primeras Jornadas Nacionales de Derecho Ambiental, 28 y 29 de noviembre de 2001, Santiago de Chile, CONAMA, CDA, Universidad de Chile, 2003, pp. 240-262.

FERNÁNDEZ BITTERLICH, P., Manual de Derecho Ambiental Chileno, Editorial

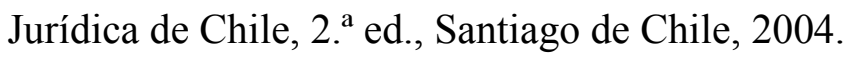

GOMIS CATALÁ, L., Responsabilidad por daños al medio ambiente, Aranzadi, Pamplona, 1998.

— "La ley de responsabilidad medioambiental en el marco del derecho de la Unión Europea”, Lozano Cutanda, B. (coord.), Comentarios a la Ley de responsabilidad medioambiental. Ley 26/2007, de 23 de octubre, Thomson Civitas, Pamplona, 2008, pp. 83-146. 
GUTIÉRREZ SAEZ, M., El Acceso a la Justicia Ambiental en Chile: Un desafío pendiente, Memoria (Grado en Ciencias Jurídicas y Sociales), Universidad de Chile, Facultad de Derecho, Santiago de Chile, 2005.

GUZMÁN ROSEN, R., Derecho Ambiental Chileno. Principios, instituciones, instrumentos de gestión, Planeta Sostenible, Santiago de Chile, 2012.

JANA LINETZKY, A., SCHWENCKE SAINT-JEAN, J. P. y VARAS BRAUN, J. A., "La responsabilidad civil en el proyecto de la ley de bases del medio ambiente: una mirada crítica”, Revista Derecho y Humanidades, núm. 2, 1992.

JARIA I MANZANO, J., "El fundamento constitucional de los derechos de participación en materia de medio ambiente y su desarrollo en la Ley 27/2006", Pigrau Solé, A. (dir.), Acceso a la información, participación pública y acceso a la justicia en materia de medio ambiente: diez años del Convenio de Aarhus, Atelier, Barcelona, 2008, pp. 119-147.

JORDANO FRAGA, J., La protección del derecho a un medio ambiente adecuado, Bosch, Barcelona, 1995.

LYON PUELMA, A., Teoría de la Personalidad, Ediciones Universidad Católica de Chile, Santiago de Chile, 1993.

MARRACO ESPINÓS, J. M., "Reflexiones sobre las dificultades del acceso a la justicia ambiental desde la perspectiva del abogado", Pigrau Solé, A. y Casado Casado, L. (dirs.), Derecho ambiental y transformaciones de la actividad de las administraciones públicas, Barcelona, Atelier, 2010, pp. 219-225.

MONTERO AROCA, J. et ál., Derecho Jurisdiccional, parte general, tomo I, Tirant Lo Blanch, 16. ${ }^{\mathrm{a}}$ ed., Valencia, 2008.

ORTELlS RAMOS, M., Introducción al Derecho Procesal, Thomson Reuters / Aranzadi, 2. ${ }^{\text {a }}$ ed., Navarra, 2011.

PEÑALVER I CABRÉ, A., "Novedades en el acceso a la justicia y a la tutela administrativa en asuntos medioambientales", Pigrau Solé, A. (dir.), Acceso a la información, participación pública y acceso a la justicia en materia de medio ambiente: diez años del Convenio de Aarhus, Atelier, Barcelona, 2008, pp. 349-403. 
PRIEUR, M., Complaints and appeals in the area of environment on the member states of the European Union, Commission of the European Community, DGXI, European Council on Environmental Law/European Environmental Law Association, 1998.

RAZQUIN LIZARRAGA, J. A. y RUIZ DE APODACA ESPINOSA, Á., Información, participación y justicia en materia de medio ambiente. Comentario sistemático a la Ley 27/2006, de 18 de julio, Thomson Aranzadi, Navarra, 2007.

RUIZ DE APODACA ESPINOSA, A., "La acción pública ambiental: una necesidad satisfecha parcialmente por la Ley 27/2006, de 18 de julio", Revista Aranzadi de Derecho Ambiental, núm. 11, 2007.

— "Nuevas perspectivas del acceso a la justicia en materia de medio ambiente", Pigrau Solé, A. y Casado Casado, L. (dirs.), Derecho ambiental y transformaciones de la actividad de las administraciones públicas, Barcelona, Atelier, 2010, pp. 187-218.

VALENZUELA FUENZALIDA, R., "La responsabilidad civil por daño ambiental", Derecho del Medio Ambiente, Fundación Facultad de Derecho, Universidad de Chile, Editorial Jurídica Conosur Ltda., Santiago de Chile, 1998, pp. 66-71.

VERGARA FISCHER, J., "La responsabilidad en la ley de bases del medio ambiente", Revista Derecho y Humanidades, núm. 2, 1992.

\section{RECURSOS EN LÍNEA}

CORDERO VEGA, L., "Tribunales Ambientales: la pieza faltante de la institucionalidad ecológica”, El Mercurio Legal (2011, 27 de noviembre). Recuperado el 18 de abril de 2012, de <http://www.elmercurio.com/Legal/Noticias/Noticias-yreportajes/2011/11/27/Tribunales-Ambientales-la-pieza-faltante-de-la-institucionalidadecologica.aspx>.

DOUGNAC RODRÍGUEZ, F., “Tribunales ambientales: sueño u operatividad”, El Mostrador (2009, 24 de noviembre). Recuperado el 15 de abril de 2012, de $<$ http://www.elmostrador.cl/opinion/2009/11/24/tribunales-ambientales-sueno-uoperatividad/>.

LEXWEB.CL (2013, 2 de abril), “Tribunal Ambiental acoge su primer caso". Recuperado el 10 de abril de 2013, de <http://www.lexweb.cl/tribunal-ambiental-acogeprimer-caso-barrick>. 
OJO CON EL PARLAMENTO Y CHILE SUSTENTABLE, (2010, 20 de agosto), "Proyecto de Ley que crea los Tribunales Ambientales". Minuta de tramitación en el Senado del Congreso Nacional. Recuperado el 11 de abril 2013, de $<$ http:/diariodelderechoambiental.bligoo.com.ar/media/users/8/417260/files/31290/Min uta-Tramitacion-Tribunales-Ambientales-Senado-Agosto-2010.pdf>.

OLIVARES CORTÉS, C., (2010, 15 de octubre), "Legitimación activa en los Tribunales Ambientales". Blog del Centro de Derecho Ambiental. Recuperado el 17 de septiembre 2012, de <http://www.derecho-ambiental.cl/2010/07/legitimacion-activa-enlos-tribunales.html>.

PROGRAMA DE DERECHO Y POLÍTICA AMBIENTAL, Facultad de Derecho, Universidad Diego Portales (2010, 27 de septiembre). Comentarios acerca del proyecto de Ley que crea los tribunales ambientales (Boletín No 6747-12). Recuperado el 30 de abril 2012, de <www.derechoambiental.udp.cl/?p=1059>.

PROGRAMA DE NACIONES UNIDAS PARA EL MEDIO AMBIENTE (2012, 20 de abril), Quinto Programa Regional de Capacitación en Derecho y Políticas Ambientales. País: Chile. Recuperado el 20 de abril 2013, de $<$ http://www.pnuma.org/deramb/documentos/legislacionporpaises/CHILE.pdf $>$.

THE ACCESS INITIATIVE (2012, 20 de abril). Sobre TAI. Recuperado el 20 de abril de 2012, de <http://www.accessinitiative.org/poverty/node/323>.

\section{NORMAS Y SENTENCIAS}

Convenio de Aarhus de 25 de junio de 1998, sobre el acceso a la información, la participación del público en la toma de decisiones y el acceso a la justicia en materia de medio ambiente.

Ley 27/2006, de 18 de julio, por la que se regulan los derechos de acceso a la información, de participación pública y de acceso a la justicia en materia de medio ambiente.

Ley 26/2007, de 23 de octubre, de Responsabilidad Medioambiental.

Ley 19.300/1994, de 9 de marzo, sobre bases del medio ambiente. 
Ley 20.417/2010, de 12 de enero, que crea el Ministerio, el Servicio de Evaluación Ambiental y la Superintendencia del Medio Ambiente.

Ley 20.283/2008, de 30 de julio, sobre recuperación del bosque nativo y fomento forestal.

Ley 19.880/2003, de 29 de mayo, que establece bases de los procedimientos administrativos que rigen los actos de los órganos de la administración del Estado.

Ley $20.600 / 2012$, de 28 de junio, que crea los tribunales ambientales.

Auto Acordado de la Corte Suprema de 24 de junio de 1992 sobre tramitación y fallo del recurso de protección de garantías constitucionales.

Sentencia de 19 de marzo de 1997. Corte Suprema. Girardi y otros con Comisión Regional de Medio Ambiente XII Región. Rol 2732-96.

Sentencia de 24 de junio de 1999. Corte de Apelaciones de Concepción. Municipalidad de Antuco con Dirección de Obras Hidráulicas. Rol 351-98.

Sentencia de 30 de agosto de 2000. Corte de Apelaciones de Concepción. Municipalidad de Santa Juana con Comisión Regional de Medio Ambiente VIII Región. Rol 252-99.

Sentencia de 30 de agosto de 2000. Corte de Apelaciones de Concepción. Municipalidad de Santa Juana con Comisión Regional de Medio Ambiente VIII Región. Rol 252-99. 